\title{
Characterization of Ceramides by Low Energy Collisional-Activated Dissociation Tandem Mass Spectrometry with Negative-ion Electrospray Ionization
}

\author{
Fong-Fu Hsu and John Turk \\ Mass Spectrometry Resource, Division of Endocrinology, Diabetes, and Metabolism, Department of Medicine, \\ Washington University School of Medicine, St. Louis, Missouri, USA
}

\begin{abstract}
Negative-ion electrospray ionization tandem quadrupole mass spectrometry provides a useful method for the structural characterization of ceramides. Fragment ions referring to the identities of the fatty acid substituent and of the long chain base of the molecules are readily available and the structure of ceramides can be easily determined. A unique fragmentation pathway which leads to formation of the fatty acid carboxylate anions $\left(\mathrm{RCO}_{2}^{-}\right)$was observed. This fragmentation is initiated by cleavage of the $\mathrm{C} 2-\mathrm{C} 3$ bond of the LCB to yield a $\mathrm{N}$-acylaminoethanol anion ([RCONHCH $\left.\mathrm{CH}_{2} \mathrm{O}\right]^{-}$), followed by rearrangement to a carboxyethylamine ([ $\left.\left.\mathrm{RCO}_{2} \mathrm{CH}_{2} \mathrm{CH}_{2} \mathrm{NH}\right]^{-}\right)$intermediate, which further dissociates to a $\mathrm{RCO}_{2}^{-}$ion. This pathway is confirmed by the CAD tandem mass spectrum of the synthetic $\mathrm{N}$-acylaminoethanol standard and of the deuterated analogs of ceramides obtained by $\mathrm{H}-\mathrm{D}$ exchange. The observation of $\mathrm{RCO}_{2}^{-}$ion species permits an unambiguous identification of the fatty acyl moiety of ceramides. Tandem mass spectrometry methods for characterization of structural isomers of ceramides using product-ion scanning and for identification of specific ceramide subclasses in biological mixtures using neutral loss scanning are also demonstrated. (J Am Soc Mass Spectrom 2002, 13, 558-570) (C) 2002 American Society for Mass Spectrometry
\end{abstract}

W e recently reported the utilization of lowenergy CAD tandem mass spectrometry with electrospray ionization (ESI) to characterize ceramides as their lithiated adduct ions in the positive ion mode. The product-ion spectra contain rich fragment ions that refer to the identities of the fatty acyl and the long chain base (LCB) substituents of the molecules and the structure of ceramides can be easily determined [1]. Ceramide gives excellent sensitivity when observed as the $[\mathrm{M}+\mathrm{H}]^{+}$species, which is very labile and easily dissociates to the $\left[\mathrm{M}+\mathrm{H}-\mathrm{H}_{2} \mathrm{O}\right]^{+}$ion [2]. In the negative ion mode, ceramide forms the $[\mathrm{M}+\mathrm{Cl}]^{-}$ion with $\mathrm{Cl}^{-}$. Ceramide also yields $[\mathrm{M}-\mathrm{H}]^{-}$ions with less sensitivity, when subjected to ESI [3-5].

Tandem sector mass spectrometric analysis of ceramide with FAB in negative-ion mode was first reported by Costello et al. [6], followed by Ann and Adams [7, 8]. The structural information obtained from the product-ion spectra was thought to be complimentary to that arising from the $[\mathrm{M}+\mathrm{Li}]^{+}$or $[\mathrm{M}+\mathrm{H}]^{+}$ions in positive-ion mode [6-8]. Recently, Raith and Neu-

Published online April 2, 2002

Address reprint requests to Dr. F.-F. Hsu, Department of Internal Medicine, Washington University School of Medicine, 660 S. Euclid, Box 8127, St. Louis, MO 63110, USA. E-mail: fhsu@im.wustl.edu bert [3, 4] and Vietzke et al. [5] reported the application of quadrupole ion-trap tandem mass spectrometric method with ESI to characterize ceramide as the $[\mathrm{M}-\mathrm{H}]^{-}$ions. However, the studies provide very limited structural information and the evidence of the proposed fragmentation pathways is inadequate. Herein, we report the application of low-energy CAD tandem mass spectrometry to the structural determination of the $[\mathrm{M}-\mathrm{H}]^{-}$ions of ceramides using ESI. This paper highlights a unique rearrangement that leads to the formation of the fatty acid carboxylate ion, with which a direct identification of the fatty acid substituent can be easily achieved. This paper also details the fragmentation pathways that lead to the ion formation using the product-ion spectra of the fragment ions generated by source CAD (pseudo-MS ${ }^{3}$ ) and of the analogous deuterium-labeling ion species obtained by $\mathrm{H}-\mathrm{D}$ exchange.

\section{Materials and Methods \\ Ceramide Standards and Abbreviations}

The $N$-oleoyl-4-sphingenine (d18:1/18:1-Cer) and $N$ tetracosenoyl-4-sphingenine (d18:1/24:1-Cer) standards were purchased from Avanti Lipid (Alabaster, $\mathrm{AL})$. Sphingosine and other ceramide standards were 


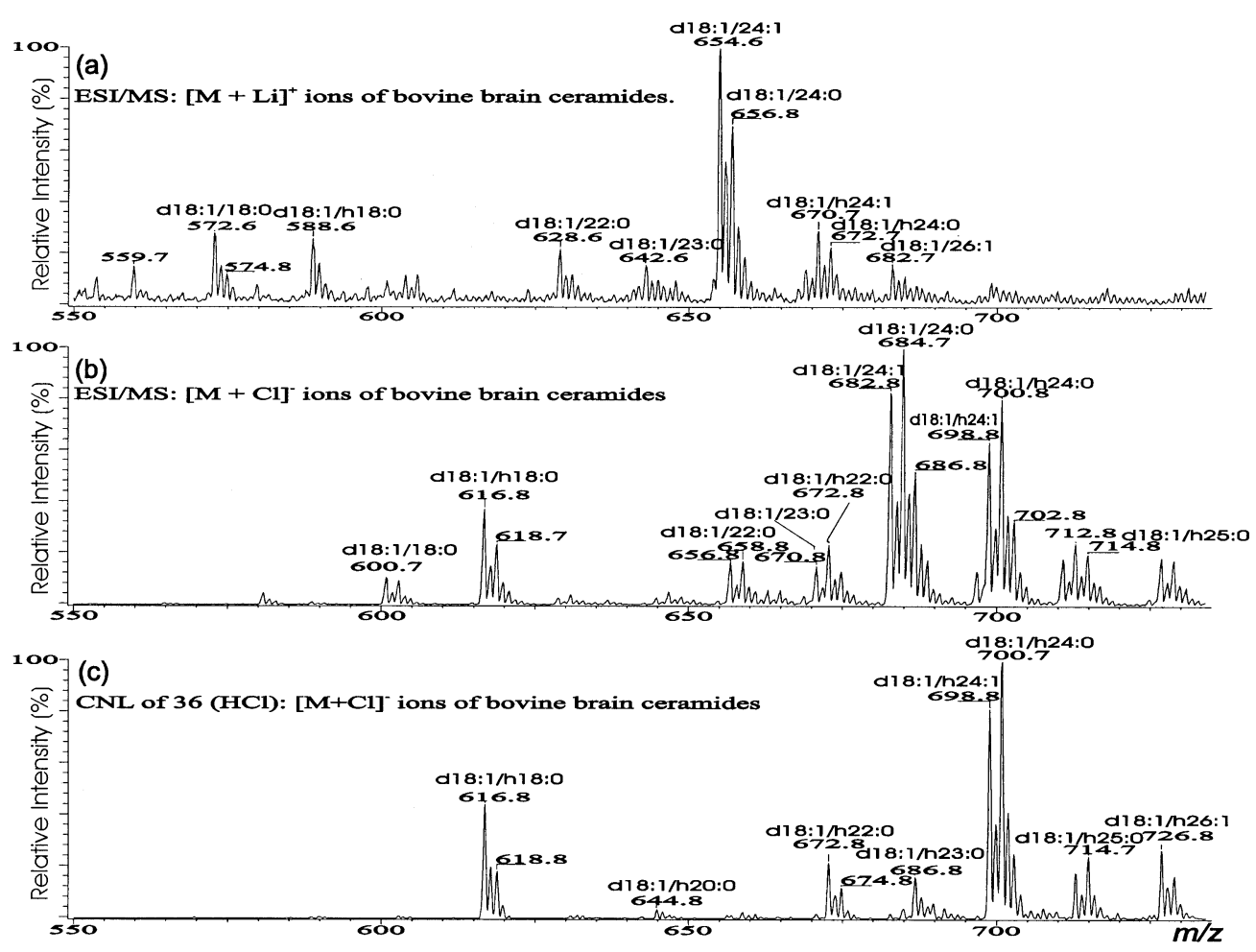

Figure 1. The ESI/MS of (a) the $[\mathrm{M}+\mathrm{Li}]^{+}$ions of bovine brain ceramides in positive-ion mode, $(\mathbf{b})$ the $[\mathrm{M}+\mathrm{Cl}]^{-}$ions of the same mixture obtained in negative-ion mode, and (c) the tandem mass spectrum of the same mixture obtained by CNL of 36 (loss of $\mathrm{H}^{35} \mathrm{Cl}$ ).

purchased from Sigma Chemical (St. Louis, MO). The $\mathrm{N}$-stearoylsphinganine(d18:0/18:0-Cer), $\mathrm{N}$-tetracosanoylsphinganine (d18:0/24:0-Cer), and sphinganine (18:0LCB) standards were prepared by hydrogenation [9] of the analogous $\mathrm{N}$-acylsphingosines. The deuteriumlabeling standards were prepared by $\mathrm{H}-\mathrm{D}$ exchange as described previously [10].

The designation of ceramide is in the form of dLCB/ FA, with d denoting a dihydroxy long chain base (LCB), namely, a 1,3-dihydroxyl-LCB, of which the 2-aminooctadec-4-ene-1,3-diol (sphing-4-enine) is designated as $\mathrm{d} 18: 1$. The sphinganine LCB is designated as d18:0. FA refers to fatty acid, which is designated as nFA for a non-hydroxylated fatty acid and hFA for an $\alpha$-hydroxy fatty acid.

\section{Synthesis and Structural Characterization of $N$-Oleoylaminoethanol Standard}

The N-oleoylaminoethanol $\left(\mathrm{C}_{17} \mathrm{H}_{33} \mathrm{CONHCH}_{2} \mathrm{CH}_{2} \mathrm{OH}\right)$ standard was synthesized using oleoyl chloride and ethanolamine. At room temperature, an equivalent oleoyl chloride (Aldrich Chemical, Milwaukee, WI) was dropwisely added to an aliquot of $0.1 \mathrm{ml}$ of ethanolamine (Aldrich Chemical) dissolved in $1 \mathrm{ml}$ chloroform. The mixture was vortexed at room temperature for 10 min. The reaction product was isolated with an Alltech (Deerfield, IL) LiChrosorb silica column $(4.6 \mathrm{~mm} \times 25$ $\mathrm{cm}, 100 \mathrm{u}$ ), isocratically, using a 1:1 (vol/vol) propanol/ hexane with $3.5 \%$ water. The flow rate was set at 2 $\mathrm{ml} / \mathrm{min}$ and UV was used as the detector. The $\mathrm{N}$ oleoylaminoethanol is eluted at $15 \mathrm{~min}$ and the overall yield of the reaction is $>60 \%$, as estimated by the HPLC peak responses. Peaks were collected and blown to dryness under a stream of nitrogen. The compound gives a $[\mathrm{M}+\mathrm{H}]^{+}$ion of $\mathrm{m} / \mathrm{z} 326$ in positive-ion mode and a $[\mathrm{M}-\mathrm{H}]^{-}$ion of $\mathrm{m} / \mathrm{z} 324$ ion in negative-ion mode by ESI/MS analysis. The structure of the product is further confirmed by proton NMR spectroscopy (NH: 5.85 ppm, OH: 2.5 ppm).

\section{Mass Spectrometry}

ESI/MS analyses were performed on a Finnigan (San Jose, CA) TSQ-7000 triple stage quadrupole mass spectrometer equipped with an electrospray ion source and controlled by Finnigan ICIS software operated on a DEC alpha station. Ceramides were dissolved in chloroform/methanol $(1 / 4)$, to a final concentration of 10 $\mathrm{pmol} / \mu \mathrm{L}$, which yields mainly the $[\mathrm{M}+\mathrm{Cl}]^{-}$and $[\mathrm{M}-$ $\mathrm{H}]^{-}$ions upon MS analysis. To enhance the signal of the $[\mathrm{M}-\mathrm{H}]^{-}$ions in most of the analyses, a voltage of 15-20 V was applied to the ion transmission octapole to induce conversion of the $\left[\mathrm{M}+\mathrm{Cl}^{-}\right.$ions to $[\mathrm{M}-\mathrm{H}]^{-}$by removal of $\mathrm{HCl}$. Samples were infused $(1 u \mathrm{~L} / \mathrm{min})$ into the ESI source, employing nitrogen as nebulizing gas and the electrospray needle was set at $4.5 \mathrm{kV}$. The heated capillary temperature was $250{ }^{\circ} \mathrm{C}$ and the mass spectrometer was tuned to unit-mass resolution. For product-ion spectra, precursor ions were selected in the 


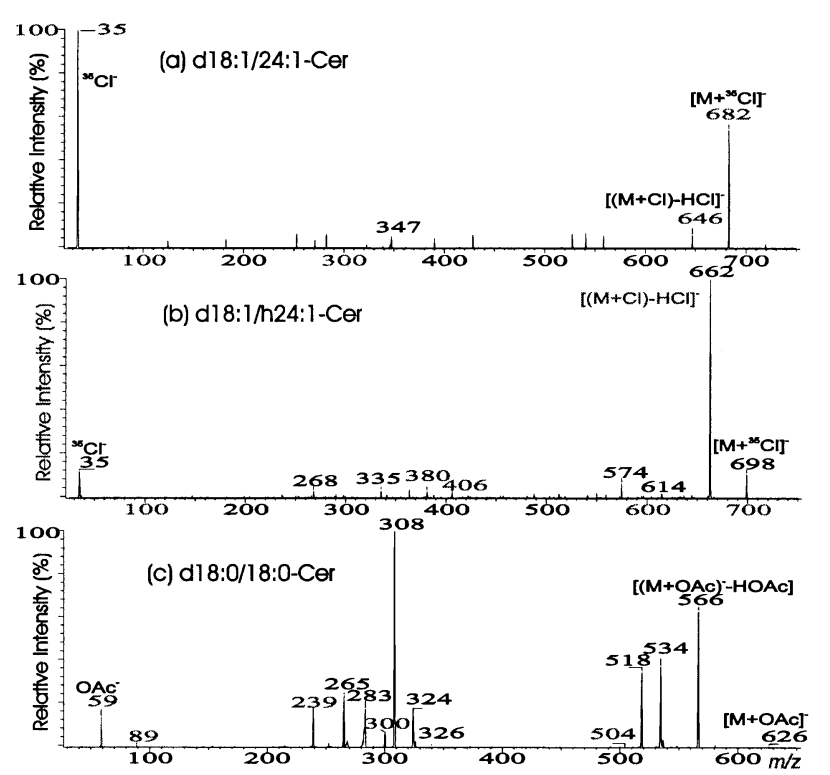

Figure 2. The product-ion spectra of (a) the $\left[\mathrm{M}+{ }^{35} \mathrm{Cl}\right]^{-}$ions of the d18:1/24:1-Cer at $\mathrm{m} / \mathrm{z} 682$, (b) the $\left[\mathrm{M}+{ }^{35} \mathrm{Cl}\right]^{-}$ions of the d18:1/h24:1-Cer at $m / z$ 698, and (c) the [M + OAc] $]^{-}$adduct ions of the d18:0/d18:0-Cer at $m / z 626$.

first quadrupole (Q1) and collided with $\operatorname{Ar}(2.3$ mtorr) in the rf-only second quadrupole (Q2) using a collision energy of $20-35 \mathrm{eV}$, and mass analyzed in the third quadrupole (Q3). For CAD tandem mass spectrometry of source-generated fragment ions (source CAD-MS ${ }^{2}$ ), a voltage of 30-35 $\mathrm{V}$ was applied to the rf-only ion transmission octapole to generate fragment ions, which were then selected in the Q1 and collided with $\mathrm{Ar}(2.3$ mtorr) in the Q2, using a collision energy of 25-35 eV. Typically, a 1-min period of signal averaging was employed for the scanned spectra and 1 to $10 \mathrm{~min}$ was employed for the tandem mass spectra.

\section{Results and Discussion}

\section{Formation of Negative Ions}

Ceramide forms adduct ion $\left([\mathrm{M}+\mathrm{X}]^{-}\right)$with various anions $\left(\mathrm{X}^{-}\right)$, such as $\mathrm{Cl}^{-}, \mathrm{CH}_{3} \mathrm{CO}_{2}^{-}$, and $\mathrm{CF}_{3} \mathrm{CO}_{2}^{-}$, when subjected to ESI in negative-ion mode. The formation of the $[\mathrm{M}+\mathrm{X}]^{-}$ions is compound dependent and the relative ion abundance varies among different ceramide subclasses. This is shown by the $\left[\mathrm{M}+\mathrm{Li}^{+}\right.$(Figure 1a), and the $[\mathrm{M}+\mathrm{Cl}]^{-}$(Figure 1b) adduct ions of bovine ceramide (from digestion of sphinogomylin). In the latter spectrum, the ion intensities of the $[\mathrm{M}+\mathrm{Cl}]^{-}$ions that reflect the d18:1/hFA-Cer are more abundant than those that reflect the d18:1/nFA-Cer. This may be attributable to the fact that the chloride affinity for d18:1/hFA-Cer in the gas phase is higher than that for d18:1/nFA-Cer [11]. CAD of the $[\mathrm{M}+\mathrm{Cl}]^{-}$or the [M + $\left.\mathrm{CF}_{3} \mathrm{CO}_{2}\right]^{-}$adduct ions of ceramides yield mainly a $\mathrm{Cl}^{-}$ (Figure 2) or $\mathrm{CF}_{3} \mathrm{CO}_{2}^{-}$ion (not shown), and structural information referring to the fatty acid and the LCB substituents is not available. As shown in Figure 2, the product ion spectrum of the $[\mathrm{M}+\mathrm{Cl}]^{-}$ions of $\mathrm{d} 18: 1 /$ 24:1-Cer at $\mathrm{m} / \mathrm{z} 682$ (Panel a) contains a major ion of $\mathrm{Cl}^{-}$ at $m / z 35$ and a weak ion at $m / z 646$, corresponding to

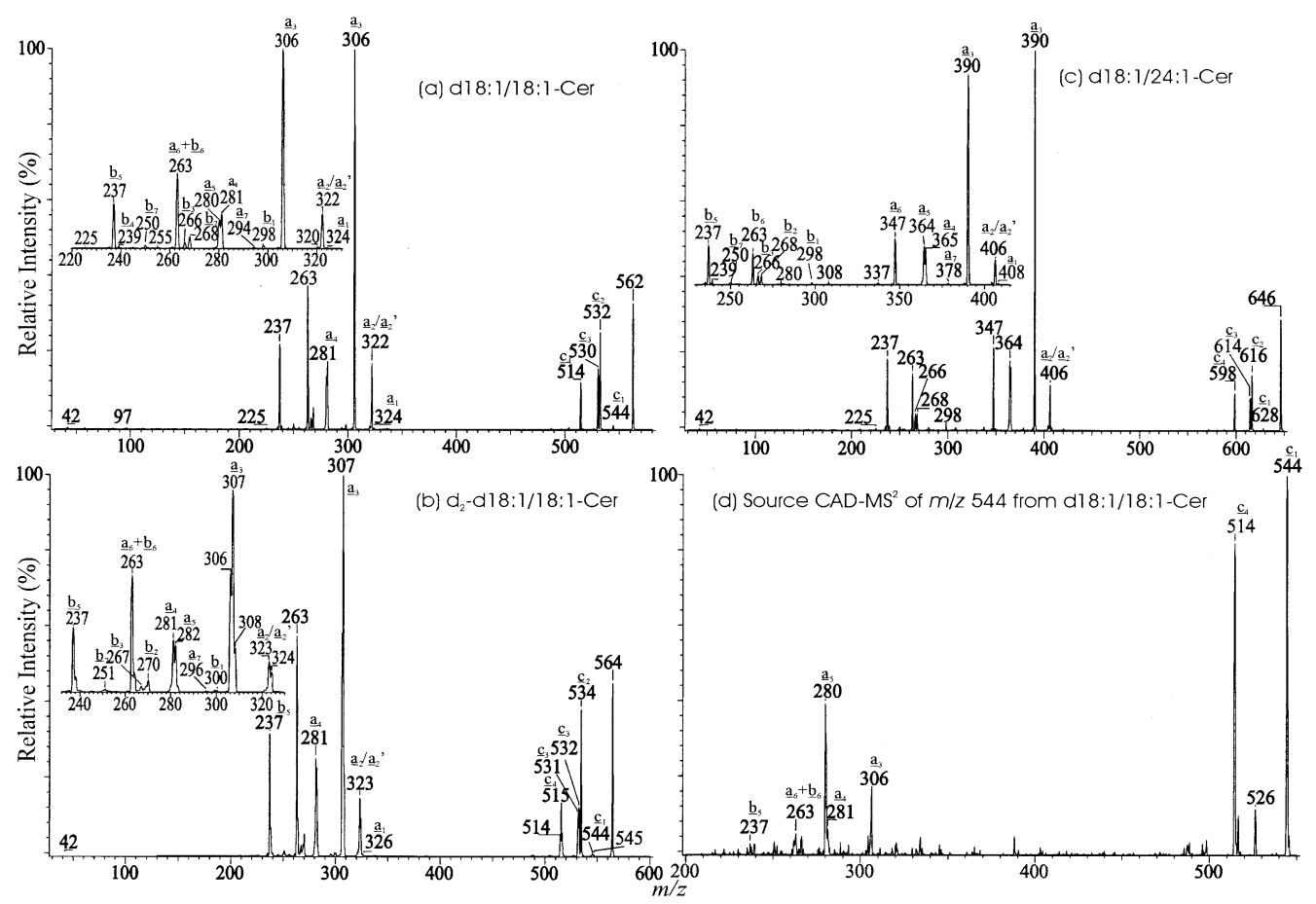

Figure 3. The product-ion spectra of the $[\mathrm{M}-\mathrm{H}]^{-}$ions of (a) d18:1/18:1-Cer at $\mathrm{m} / \mathrm{z} 562$, (b) $\mathrm{d}_{2}$-d18:1/18:1-Cer at $\mathrm{m} / \mathrm{z} 564$, (c) d18:1/24:1-Cer at $\mathrm{m} / \mathrm{z}$ 646, and (d) the source CAD product-ion spectrum of $m / z 544$, generated by source CAD of d18:1/18:1-Cer. 


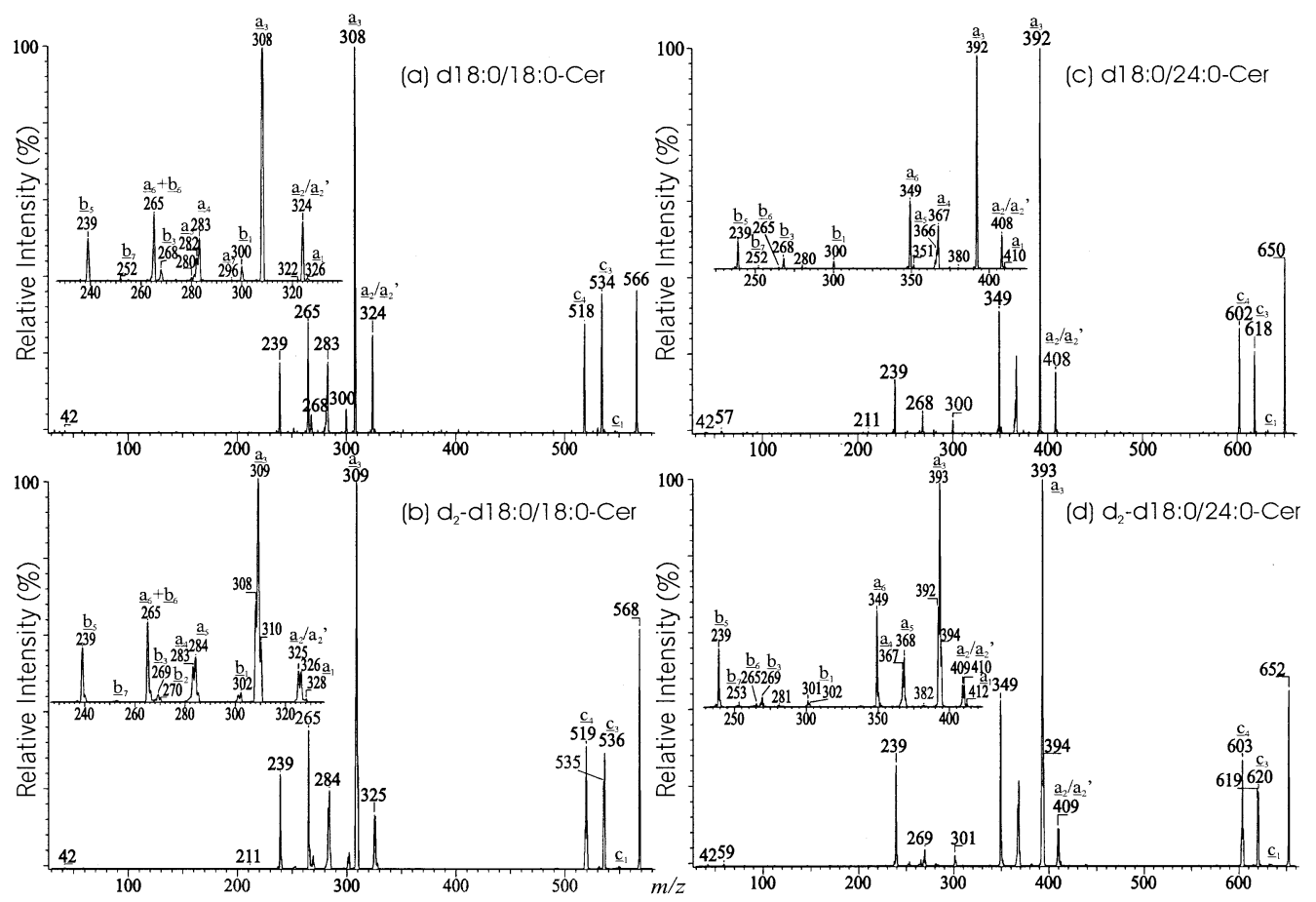

Figure 4. The product-ion spectra of the $[\mathrm{M}-\mathrm{H}]^{-}$ions of (a) d18:0/18:0-Cer at $\mathrm{m} / \mathrm{z} 566$, (b) $\mathrm{d}_{2}$-d18:0/18:0-Cer at $\mathrm{m} / \mathrm{z}$ 568, (c) d18:0/24:0-Cer at $\mathrm{m} / \mathrm{z}$ 650, and (d) $\mathrm{d}_{2}$-d18:0/24:0-Cer at $\mathrm{m} / \mathrm{z}$ 652.

loss of $\mathrm{HCl}\left([\mathrm{M}+\mathrm{Cl}]^{-}-\mathrm{HCl}\right)$, whereas the spectrum of $\mathrm{d} 18: 1 / \mathrm{h} 24: 1-$ Cer at $m / z 698$ (Panel b) is dominated by $\mathrm{m} / \mathrm{z} 662\left([\mathrm{M}+\mathrm{Cl}]^{-}-\mathrm{HCl}\right)$, and the $\mathrm{Cl}^{-}$ion of $\mathrm{m} / \mathrm{z} 35$ is less abundant. The preferential loss of $\mathrm{HCl}$ for the $\mathrm{d} 18: 1 /$ hFA-Cer over the d18:1/FA-Cer subclass is also demonstrated by the tandem mass spectrum obtained by neutral loss of 36 (Figure 1c), in which ions reflecting the $[\mathrm{M}+\mathrm{Cl}]^{-}$ions of the $\mathrm{d} 18: 1 / \mathrm{hFA}-\mathrm{Cer}$ species become dominant. The lack of the structural information of the $[\mathrm{M}+\mathrm{Cl}]^{-}$adduct ions upon CAD has been reported for various compounds [11, 12], and may be attributable to the fact that the ion is not stable. This is also consistent with the notion that the $[\mathrm{M}+\mathrm{Cl}]^{-}$ions can be easily converted to the $[\mathrm{M}-\mathrm{H}]^{-}$ions by source CAD (Figure 9a), using a collision energy as low as 15 $\mathrm{eV}$. In contrast, the $\left[\mathrm{M}+\mathrm{CH}_{3} \mathrm{CO}_{2}\right]^{-}$adduct ions of the (a)

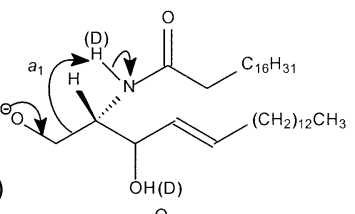

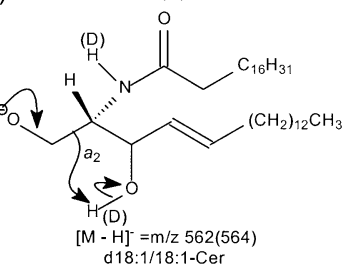

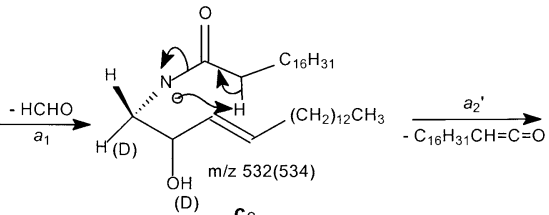

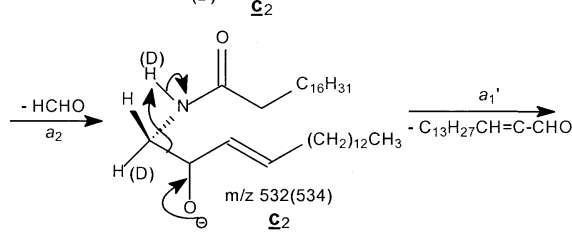<smiles>C/C=C/C(O)C(O)O</smiles>
$\underline{\mathbf{b}}_{2}$

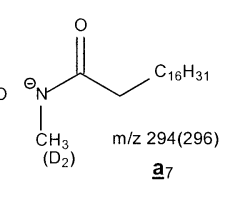

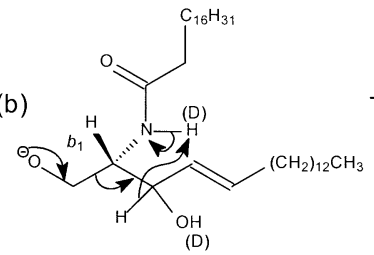

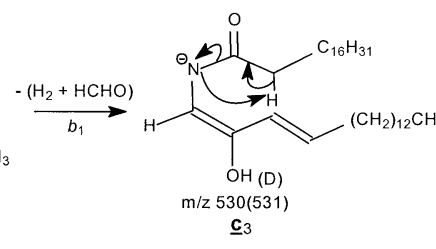

$\underline{\mathbf{c}}_{3}$

1. Ion designation: symbols with script a are fatty a cid-related ions symbols with script b are long-chain $\underline{b}$ ase-related ions

symbols with script c are common ions
2. Masses in parentheses arise from d-labeling analogs. In some cases multiple masses were observed, probably due to hydrogen scramblings, which may account for a few mass discrepancies 


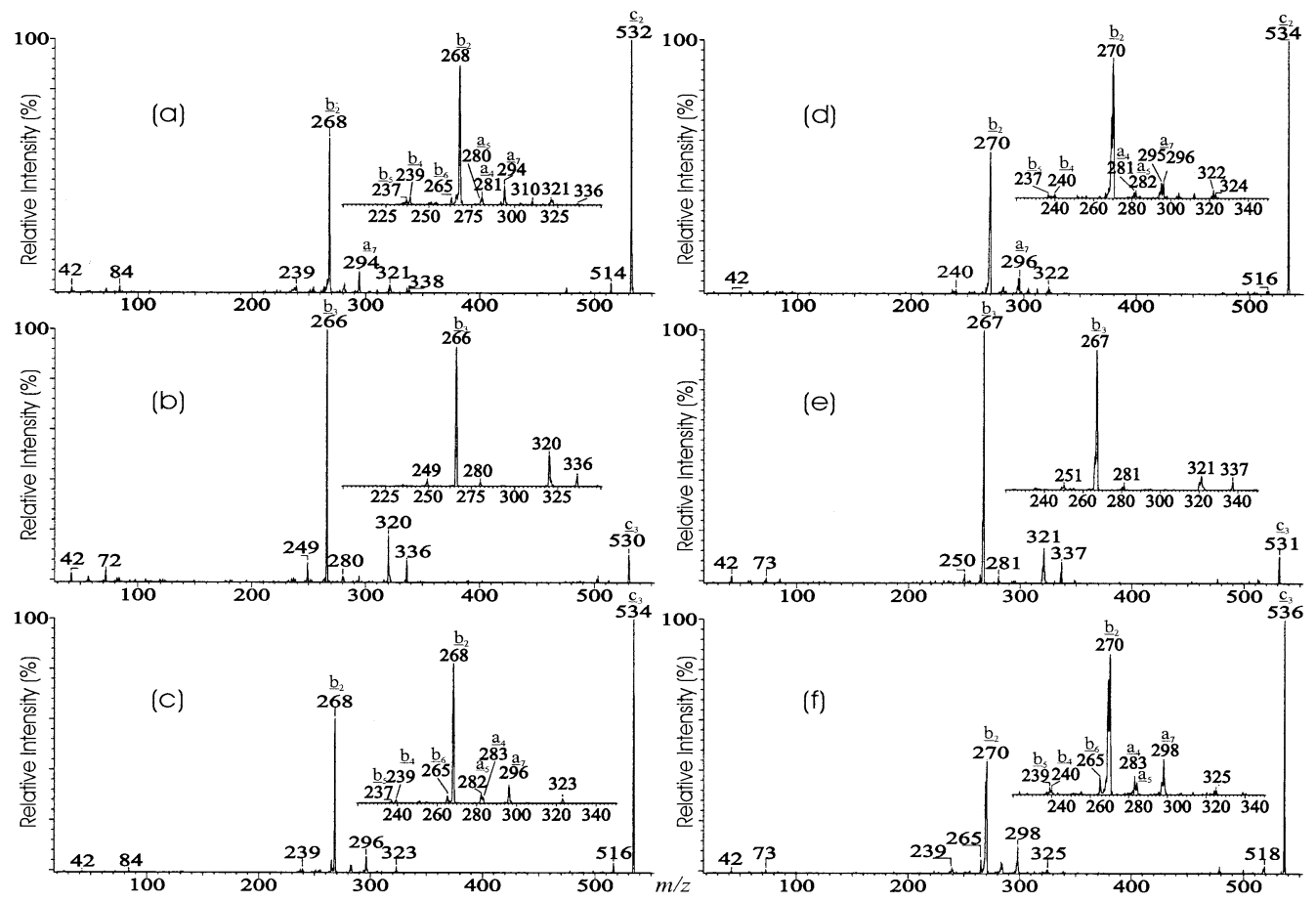

Figure 5. The source-CAD product-ion spectra of (a) the $m / z 532$, (b) the $m / z 530$, (c) the $m / z 534$ ion, (d) $m / z$ 534, (e) $m / z 531$, and (f) $m / z 536$. The $m / z 532$ (a) and 530 (b) were generated by source CAD of the d18:1/18:1-Cer $(m / z 562)$, and are reflecting loss of $\mathrm{HCHO}$ and $\left(\mathrm{H}_{2}+\mathrm{HCHO}\right)$, respectively. The $\mathrm{m} / \mathrm{z} 534$ (c) was generated by CAD of the d18:0/18:0-Cer $(\mathrm{m} / \mathrm{z} 566)$, and corresponds to loss of $\left(\mathrm{H}_{2}+\right.$ HCHO). The $m / z 534$ (d), 531 (e), and 536 (f) are the analogous ions to $m / z 532$ (a), 530 (b), and 534 (c), respectively, and were generated by source CAD of the corresponding $\mathrm{d}_{2}$-labeling ceramides.

(a)

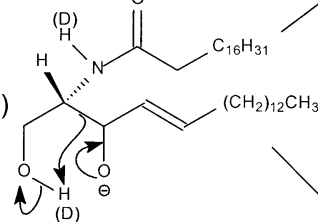

今)

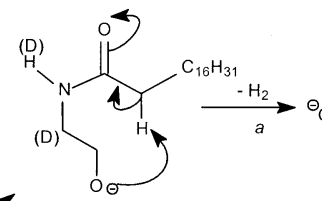

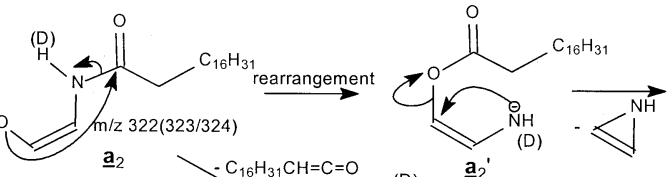

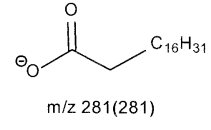

$\underline{\mathrm{a}}_{4}$

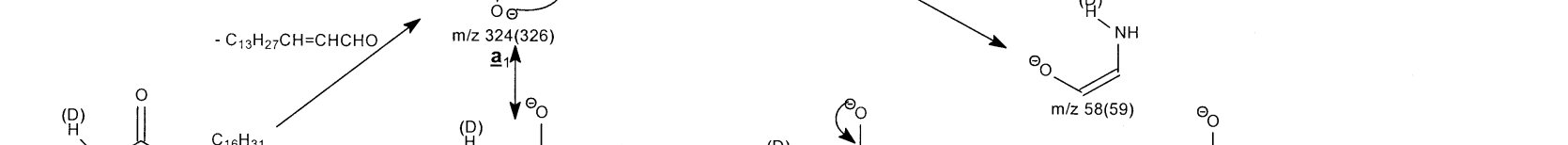

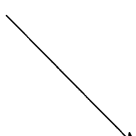<smiles>C/C(=C\CCCCCO)N([Tl])C([Hg])CO</smiles>

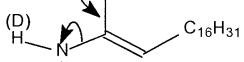<smiles>C=CN</smiles><smiles>O=CC=CCCCCCO</smiles>

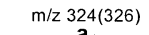<smiles>CCCCCCC(=O)N1CCCCC1</smiles><smiles></smiles>

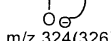

$\underline{\mathbf{a}}_{1}$

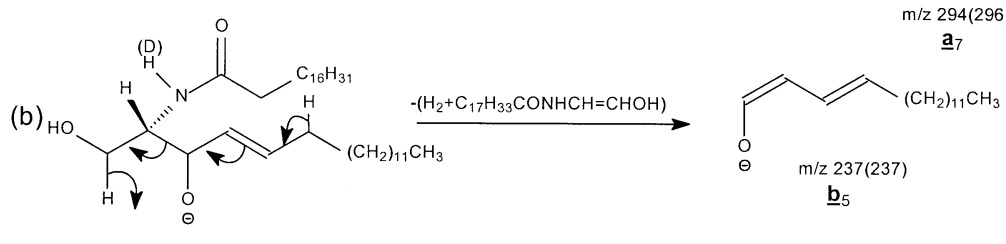

Footnotes same as Scheme 1 

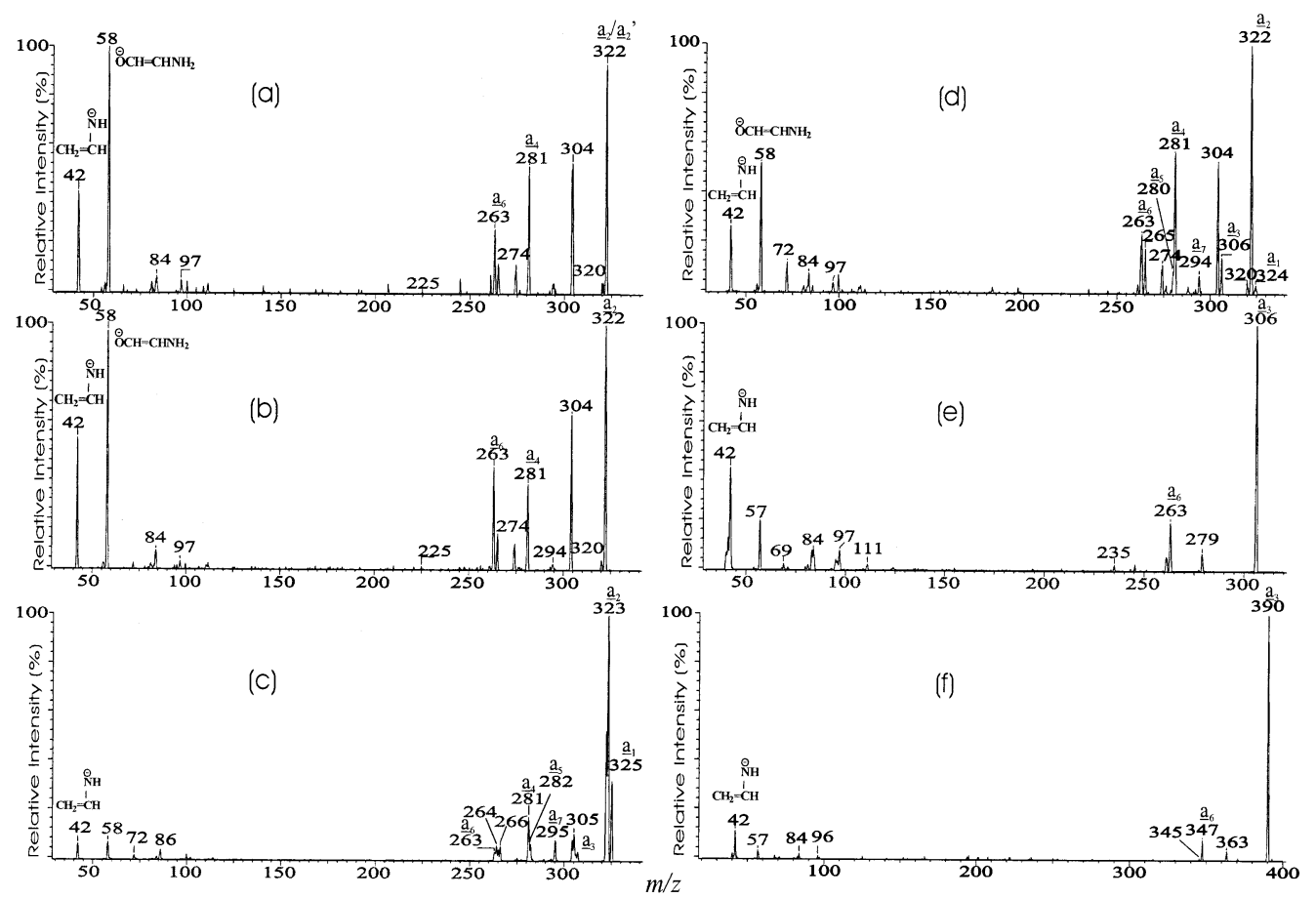

Figure 6. The source-CAD product-ion spectra of (a) the $\mathrm{m} / \mathrm{z} 322$, generated by source CAD of d18:1/18:1-Cer at $m / z 562$, (b) the $m / z 322$ ion, generated from source CAD of the standard of $\mathrm{N}$-oleoylaminoethanol at $\mathrm{m} / \mathrm{z} 324$, (c) the deprotonated $\mathrm{d}_{1}-\mathrm{N}$-oleoylaminoethanol anion at $\mathrm{m} / \mathrm{z} 325$, prepared by $\mathrm{H}-\mathrm{D}$ exchange, $(\mathbf{d})$ the $[\mathrm{M}-\mathrm{H}]^{-}$ion of $N$-oleoylaminoethanol at $\mathrm{m} / \mathrm{z} 324$. (e) and (f) are the source-CAD product-ion spectra of the $\mathrm{m} / \mathrm{z} 306$ and 390 ions, generated from source CAD of $\mathrm{d} 18: 1 / 18: 1-$ Cer at $m / z 562$ and of d18:1/24:1-Cer at $m / z$ 646, respectively.

d18:0/18:0-Cer at $m / z 626$ (Figure 2c) yield product ion spectra similar to that obtained from the $[\mathrm{M}-\mathrm{H}]^{-}$ions at $\mathrm{m} / \mathrm{z} 566$ (Figure 4a), and provide information for structural characterization.

\section{The Charge-Site(s) of the $[\mathrm{M}-\mathrm{H}]^{-}$Ions}

Ann and Adams proposed the charge-remote fragmentation (CRF) pathways for the fragment ions formed by the $[\mathrm{M}-\mathrm{H}]^{-}$ions of ceramides following CAD. The anionic charge was thought to delocalize at the carbonyl and $\alpha$-carbon of the fatty acyl substituent $[7,8]$. This charge-site suggests that one of the $\alpha$-hydrogen in the fatty acyl chain, instead of an exchangeable hydrogen has been lost for the $[\mathrm{M}-\mathrm{H}]^{-}$formation. However, the ESI/MS of the H-D exchanged analogs of d18:1/nFACer and d18:1/hFA-Cer showed a $2 \mathrm{u}$ and $3 \mathrm{u}$ mass shift, respectively, for the $[\mathrm{M}-\mathrm{H}]^{-}$ions (data not shown), indicating that the charge is more likely to reside at one of the exchangeable hydrogen sites. Raith and Neubert suggested that the anionic charge is localized at the amide, where the proton was lost. This conclusion was based on the finding that the $[\mathrm{M}-\mathrm{H}]^{-}$ ion of ceramide became unobservable when the amide proton was substituted by an alkyl chain [4]. However, the evidence is inadequate and the concept of localizing the negative charge at the amide instead of the alkyl alcohol charge-site would contradict the fact that gas phase ion of $\mathrm{RO}^{-} \mathrm{H}^{+}$is more acidic than $\mathrm{R}_{1} \mathrm{R}_{2} \mathrm{~N}^{-} \mathrm{H}^{+}$
[13]. We suggest that the negative-charge resides on the sites, where the exchangeable protons can be accountable for the proton loss. The various charge sites also account for the various fragment ions observed in the product-ion spectra of ceramides. The fragmentation pathways for the ion formation may mainly involve the charge-driven fragmentation (CDF) process, in addition to the CRF process suggested by Ann and Adams [7, 8].

\section{Structural Characterization by Tandem Mass Spectrometry}

$\mathrm{N}$-acylsphingosines and $\mathrm{N}$-acylsphinganines Although the CAD product-ion spectra of $\left[\mathrm{M}+\mathrm{Li}^{+}\right.$ions of ceramides obtained by high-energy are readily distinguishable from that by low-energy [1, 6-8], the product-ion spectra of the $[\mathrm{M}-\mathrm{H}]^{-}$ions of ceramides from low-energy CAD obtained in this study are similar to that arising from high-energy [6-8]. As shown in Figure $3 \mathrm{a}$, the $[\mathrm{M}-\mathrm{H}]^{-}$ions of $N$-oleoylsphingenine (d18:1/18:1-Cer) at $m / z 562$ yield a weak ion at $m / z 544$ $\left(\underline{c}_{1}\right)$, corresponding to loss of $\mathrm{H}_{2} \mathrm{O}$, followed by a $\mathrm{HCHO}$ loss to give rise to the $\mathrm{m} / \mathrm{z} 514$ ion $\left(\underline{c}_{4}\right)$, which dissociates to $m / z 250\left(\underline{b}_{7}\right)$ by loss of the fatty acyl moiety as a ketene (loss of $\mathrm{C}_{16} \mathrm{H}_{31} \mathrm{CH}=\mathrm{C}=\mathrm{O}$ ). The $\mathrm{m} / z 544$ ion also gives $\mathrm{m} / \mathrm{z} 263\left(b_{6}\right)$ by elimination of the fatty acyl moiety as an amide (loss of $\mathrm{C}_{17} \mathrm{H}_{33} \mathrm{CONH}_{2}, 281 \mathrm{Da}$ ). The fragmentation pathways are supported by source CAD product- 
Table 1. Major fragment ions observed for various ceramide

\begin{tabular}{|c|c|c|c|c|c|c|c|c|c|c|}
\hline \multicolumn{3}{|c|}{ Ceramide species } & \multicolumn{8}{|c|}{ Fragment ions from } \\
\hline $\begin{array}{l}{[\mathrm{M}-\mathrm{H}]^{-}} \\
(\mathrm{m} / \mathrm{z})\end{array}$ & Fatty acid & LCB & \multicolumn{5}{|c|}{ Common ions $(\mathrm{m} / \mathrm{z})$} & \multicolumn{3}{|r|}{ LCB ions } \\
\hline \multirow[t]{2}{*}{$\bar{A}$} & & & ${ }^{\mathrm{d}} \underline{c}_{1}{ }^{\mathrm{a}}$ & $\underline{c}_{2}$ & $\underline{c}_{3}$ & $\underline{c}_{4}$ & $\underline{c}_{5}$ & ${ }^{\mathrm{d}} \underline{b}_{1}$ & $\underline{b}_{2}$ & $\underline{b}_{3}$ \\
\hline & & & {$\left[\mathrm{A}-\mathrm{H}_{2} \mathrm{O}\right]^{-}$} & {$\left[\mathrm{A}-\mathrm{H}_{2} \mathrm{CO}\right]^{-}$} & {$\left[\mathrm{A}-\mathrm{H}_{2}-\mathrm{H}_{2} \mathrm{CO}\right]^{-}$} & {$\left[\mathrm{A}-\mathrm{H}_{2} \mathrm{O}-\mathrm{H}_{2} \mathrm{CO}\right]^{-}$} & $c_{1}-\mathrm{H}_{2} \mathrm{O}$ & {$[\mathrm{LCB}-\mathrm{H}]^{-}$} & $b_{1}-\mathrm{H}_{2} \mathrm{CO}$ & $b_{1}-\mathrm{H}_{2}-\mathrm{H}_{2} \mathrm{CO}$ \\
\hline 674 & 26.0 & d18:1 & 656 & 644 & 642 & 626 & & 298 & 268 & 266 \\
\hline 648 & $24: 0$ & d18:1 & 630 & 618 & 616 & 600 & & 298 & 268 & 266 \\
\hline 646 & $24: 1$ & d18:1 & 628 & 616 & 614 & 598 & & 298 & 268 & 266 \\
\hline 562 & $18: 1$ & d18:1 & 544 & 532 & 530 & 514 & & 298 & 268 & 266 \\
\hline 650 & $24: 0$ & d18:0 & 632 & & 618 & 602 & & 300 & & 268 \\
\hline 566 & $18: 0$ & d18:0 & 548 & & 534 & 518 & & 300 & & 268 \\
\hline 662 & h24:1 & d18:1 & 644 & 632 & 630 & 614 & & 298 & 268 & 266 \\
\hline 664 & h24:0 & d18:1 & 646 & 634 & 632 & 616 & & 298 & 268 & 266 \\
\hline 580 & h18:0 & d18:1 & 562 & 550 & 548 & 532 & & 298 & 268 & 266 \\
\hline 666 & h24:0 & d18:0 & 648 & & 634 & 618 & 600 & 300 & & 268 \\
\hline 582 & h18:0 & d18:0 & 564 & & 550 & 534 & 516 & 300 & & 268 \\
\hline 648 & $24: 1$ & $\mathrm{~d}_{2}-\mathrm{d} 18: 1$ & 629 & 618 & 616,615 & 599 & & 299,300 & 270 & 267 \\
\hline 564 & $18: 1$ & $\mathrm{~d}_{2}-\mathrm{d} 18: 0$ & 565 & 534 & 532,532 & 515 & & 299,300 & 270 & 267 \\
\hline 652 & $24: 0$ & $\mathrm{~d}_{2}-\mathrm{d} 18: 0$ & 633 & & 620,619 & 603 & & 301,302 & & 269 \\
\hline 568 & $18: 0$ & $\mathrm{~d}_{2}-\mathrm{d} 18: 0$ & 549 & & 536,535 & 519 & & 301,302 & & 269 \\
\hline 665 & $d_{1}-h 24: 1$ & $\mathrm{~d}_{2}-\mathrm{d} 18: 1$ & 646,645 & 635 & 633,632 & 615 & & 301 & 271 & 268 \\
\hline 583 & $d_{1}-h 18: 0$ & $\mathrm{~d}_{2}-\mathrm{d} 18: 1$ & 564,563 & 553 & 551,550 & 534,533 & 301 & 271 & 268 & 240 \\
\hline 669 & $d_{1}-h 24: 0$ & $\mathrm{~d}_{2}-\mathrm{d} 18: 0$ & 650 & & 636 & 620 & 601 & 303 & & 270 \\
\hline 585 & $d_{1}-h 18: 0$ & $\mathrm{~d}_{2}-\mathrm{d} 18: 0$ & 566 & & 552 & 536 & 517 & 303 & & 270 \\
\hline
\end{tabular}

a Detectable $=\mathrm{d}$

${ }^{\mathrm{b}} \mathrm{NAE}=\mathrm{N}$-acylaminoethanol.

ion spectrum of the $m / z 544$ ion (Figure 3d), generated by source CAD of $\mathrm{m} / \mathrm{z} 562$ and are similar to that reported for the lithiated ceramides in positive-ion mode [1]. The $\mathrm{H}_{2} \mathrm{O}$ loss leading to the $m / z 544$ ion from $\mathrm{m} / \mathrm{z} 562$ may involve several pathways. This is based on the observation of both the $m / z 545$ and 544 ions, which respectively reflect the loss of $\mathrm{HDO}$ and $\mathrm{D}_{2} \mathrm{O}$, in the product-ion spectrum of the $[\mathrm{M}-\mathrm{H}]^{-}$ions of the $\mathrm{d}_{2}$-d18:1/18:1-Cer at $m / z 564$ (Figure $3 b$ ), prepared by $\mathrm{H}-\mathrm{D}$ exchange, and consistent with the results previously reported [1].

Two interesting ions corresponding to loss of 30 $\left([\mathrm{M}-\mathrm{H}-30]^{-}\right)$and of $32 \mathrm{u}\left([\mathrm{M}-\mathrm{H}-32]^{-}\right)$, which were observed in the high-energy CAD product-ion spectra of the $[\mathrm{M}-\mathrm{H}]^{-}$ions of $\mathrm{d} 18: 1 / \mathrm{nFA}-\mathrm{Cer}$ are also present $[7,8]$. The two ions were observed at $m / z 532$ and 530 in the spectrum of d18:1/18:1-Cer (Figure 3a) and have been suggested to arise from a $\mathrm{HCHO}$ and a $\mathrm{CH}_{3} \mathrm{OH}$ loss, respectively $[3,4,7,8]$. However, the mechanism(s) leading to the formation have not been reported. We suggest that the former ion arises from cleavage of the $\mathrm{C} 1-\mathrm{C} 2$ bond of the LCB with reattachment of one of the exchangeable hydrogen to C-2 carbon of the LCB to constitute a 1-N-oleoylaminoheptadec-3-ene-2-ol anion ( $\underline{c}_{2}$ ion, Scheme 1a). The loss is consistent with the observation of the $\mathrm{m} / \mathrm{z} 534$ ion ([564 - HCHO]) in Figure $3 b$, and of the $m / z 616$ ion in the product-ion spectrum of d18:1/24:1-Cer (Figure 3c). The fragmentation pathway is also consistent with the presence of the $m / z 268\left(\underline{b}_{2}\right)$ and $294\left(\underline{a}_{7}\right)$ ions in the source CAD product-ion spectrum of the $\mathrm{m} / \mathrm{z} 532$ ion
(Figure 5a). The $m / z 268$ ion $\left(\underline{b}_{2}\right)$ probably arises from further loss of the fatty acyl moiety as a ketene and the $m / z 294$ ion $\left(\underline{a}_{7}\right)$, arises from loss of the LCB as an aldehyde (Scheme 1a).

The $m / z 530$ ion was previously suggested to arise from $m / z 562$ by a direct loss of $\mathrm{CH}_{3} \mathrm{OH}[7,8]$. However, this loss appears to be very unlikely. The product-ion spectrum of the $\mathrm{d}_{2}$-d18:1/18:1-Cer (Figure $3 \mathrm{~b}$ ) contains two analogous ions at $m / z 531$ and 532, reflecting loss of $33 \mathrm{u}$ and $32 \mathrm{u}$, respectively. We suggest that the $m / z 531$ ion arises from loss of a HD, involving the exchangeable hydrogen at the amide along with loss of $\mathrm{HCHO}$ (Scheme 1b). This mechanism is supported by the product-ion spectrum of $m / z 531$ (Figure 5e), generated by source CAD of the $\mathrm{d}_{2}$-d18:1/18:1-Cer. The spectrum contains the $m / z 267$ ion $\left(\underline{b}_{3}\right)$, arising from further loss of the fatty acyl moiety as a ketene (Scheme $\mathbf{1 b}$ ), and the $\mathrm{m} / \mathrm{z} 321$ ion, probably arising from further loss of the LCB as an alkene (loss of $\left.\mathrm{CH}_{3}\left(\mathrm{CH}_{2}\right)_{12} \mathrm{CH}=\mathrm{CH}_{2}\right)$. The source CAD product-ion spectrum of the $m / z 532$ ion (data not shown) arising from the same loss with no involvement of the exchangeable hydrogen (loss of $\mathrm{HCHO}$ and $\mathrm{H}_{2}$ ) is similar to that from $m / z 531$, indicating that the two ions may be structurally identical. An alternative pathway for the ion formation can be speculated as a two-step process, which involves the primary loss of a HCHO followed by loss of $\mathrm{H}_{2}$ or HD to yield $m / z 532$ or 531 . However, the source-CAD product-ion spectra of $\mathrm{m} / \mathrm{z} 532$ (562 - HCHO) (Figure 5a) and $530\left[562-\left(\mathrm{H}_{2}+\mathrm{HCHO}\right)\right]$ (Figure $\left.5 \mathrm{~b}\right)$ are readily distinguishable. These results support the idea that the 
standards in negative-ion mode

\begin{tabular}{|c|c|c|c|c|c|c|c|c|c|c|c|c|}
\hline \multicolumn{13}{|c|}{$\mathrm{CAD}$ of $[\mathrm{M}-\mathrm{H}]^{-}$} \\
\hline \multicolumn{4}{|l|}{$(\mathrm{m} / \mathrm{z})$} & \multicolumn{9}{|c|}{ FA ions $(\mathrm{m} / \mathrm{z})$} \\
\hline$\underline{\underline{b}}_{4}$ & $\underline{b}_{5}$ & $\underline{b}_{6}$ & ${ }^{\mathrm{d}} \underline{b}_{7}$ & ${ }^{\mathrm{d}} \underline{a}_{1}$ & $\underline{a}_{2}$ & $\underline{a}_{3}$ & $\underline{a}_{4}$ & $\underline{a}_{5}$ & $\underline{a}_{6}$ & $\underline{a}_{7}$ & $\underline{a}_{8}$ & $\underline{a}_{9}$ \\
\hline \multirow[t]{7}{*}{$b_{2}-29$} & $b_{4}-H_{2}$ & $c_{1}-\mathrm{R}_{1} \mathrm{CONH}_{2}$ & $c_{4}-\mathrm{R}_{1} \mathrm{CH}=\mathrm{CO}$ & {$[\mathrm{NAE}-\mathrm{H}]^{\mathrm{b}}$} & $a_{1}-\mathrm{H}_{2}$ & $a_{1}-\mathrm{H}_{2} \mathrm{O}$ & $\mathrm{RCO}_{2}^{-}$ & $\mathrm{RCONH}^{-}$ & $a_{3}-43$ & $c_{2}-238$ & A-CO-LCB & $a_{3}-\mathrm{H}_{2} \mathrm{O}$ \\
\hline & 237 & 263 & 250 & 436 & 434 & 418 & 393 & 392 & 375 & 406 & & \\
\hline & 237 & 263 & 250 & 410 & 408 & 392 & 367 & 366 & 349 & 380 & & \\
\hline & 237 & 263 & 250 & 408 & 406 & 390 & 365 & 364 & 347 & 378 & & \\
\hline & 237 & 263 & 250 & 324 & 322 & 306 & 281 & 280 & 263 & 294 & & \\
\hline & 239 & 265 & 252 & 414 & 408 & 392 & 367 & 366 & 349 & & & \\
\hline & 239 & 265 & 252 & 326 & 324 & 308 & 283 & 282 & 265 & & & \\
\hline 239 & 237 & 263 & 250 & 424 & 422 & 406 & 381 & 380 & 363 & & 335 & 388 \\
\hline 239 & 237 & 263 & 250 & 426 & 424 & 408 & 383 & 382 & 365 & & 337 & 390 \\
\hline \multirow[t]{7}{*}{239} & 237 & 263 & 250 & 342 & 340 & 324 & 299 & 298 & 281 & & 253 & 306 \\
\hline & 239 & 265 & 252 & 426 & 424 & 408 & 383 & 382 & 365 & & 337 & 390 \\
\hline & 239 & 265 & 252 & 342 & 340 & 324 & 299 & 298 & 281 & & 253 & 306 \\
\hline & 237 & 263 & 251 & 410 & 408,407 & 391,390 & 367 & 366 & 347 & 380 & & \\
\hline & 237 & 263 & 251 & 326 & 324,323 & 307,306 & 281 & 282 & 263 & 296 & & \\
\hline & 239 & 265 & 253 & 412 & 410,409 & 393,392 & 367 & 368 & 349 & & & \\
\hline & 239 & 265 & 253 & 328 & 326,325 & 309,308 & 283 & 284 & 265 & & & \\
\hline 240 & 237 & 263 & 251 & 427 & 424,423 & 407 & 382 & 381 & 363 & & 335 & 389,388 \\
\hline \multirow[t]{3}{*}{237} & 263 & 251 & 345 & 342,341 & 325 & 300 & 299 & 281 & & 253 & 307,306 & \\
\hline & 239 & 265 & 253 & 429 & 426 & 409 & 384 & 384 & 365 & & 337 & 391,390 \\
\hline & 239 & 265 & 253 & 345 & 342 & 325 & 300 & 300 & 281 & & 253 & 307,306 \\
\hline
\end{tabular}

fragmentation pathway for formation of the $[(\mathrm{M}-\mathrm{H})-$ $\left.\left(\mathrm{H}_{2}+\mathrm{HCHO}\right)\right]^{-}$ion is different from that of $[(\mathrm{M}-\mathrm{H})$ $-\mathrm{HCHO}^{-}$.

One of the most interesting findings in this study is that a unique carboxylate ion $\left(\mathrm{RCO}_{2}^{-}\right)$at $\mathrm{m} / \mathrm{z} 281\left(\underline{a}_{4}\right)$, reflecting the 18:1-fatty acyl substituent is observed in the product-ion spectrum of $\mathrm{d} 18: 1 / 18: 1-C e r$ (Figure 3a). An analogous ion at $m / z 365\left(\underline{a}_{4}\right)$, reflecting a 24:1-fatty acyl substituent was also observed for d18:1/24:1-Cer (Figure 3c). This ion is of low-abundance in the product-ion spectrum obtained by highenergy CAD and has not been reported $[7,8]$. The ion was also observed in the tandem mass spectrum obtained by ion-trap mass spectrometry [3-5] and has been mistakenly assigned as an amide radical anion by Vietzke et al. [5]. The origin of the ion may derive from the initial cleavage of the $\mathrm{C} 2-\mathrm{C} 3$ bond to form a $\mathrm{N}$-oleoylaminoethanol anion $\left(\mathrm{C}_{17} \mathrm{H}_{33} \mathrm{CONHCH}_{2} \mathrm{CH}_{2} \mathrm{O}^{-}\right)$ of $m / z 324\left(\underline{a}_{1}\right.$, Scheme 2a) by loss of the LCB as an aldehyde $\left(\mathrm{CH}_{3}\left(\mathrm{CH}_{2}\right)_{12} \mathrm{CH}=\mathrm{CHCHO}, 238 \mathrm{Da}\right)$. This bond cleavage also gives rise to $m / z 237$ $\left(\left[\mathrm{CH}_{3}\left(\mathrm{CH}_{2}\right)_{12} \mathrm{CH}=\mathrm{CHCHO}-\mathrm{H}\right]^{-}\right) \quad\left(\underline{b}_{5}\right.$, Scheme $\left.2 \mathbf{b}\right)$, probably representing a deprotonated aldehyde ion that can be used to identify the d18:1-LCB. An analogous ion at $m / z 239$ reflecting the 18:0-LCB was observed for d18:0/nFA (Figure $4 a-d$ ). Further loss of $\mathrm{H}_{2}$ from the $\mathrm{m} / \mathrm{z} 324$ ion gives rise to a deprotonated $N$-oleoylaminoethylen-1-ol at $m / z 322$ $\left(\mathrm{C}_{17} \mathrm{H}_{33} \mathrm{CONHCH}=\mathrm{CHO}^{-}\right)\left(\underline{a}_{2}\right)$. The $\mathrm{m} / \mathrm{z} 322$ ion may rearrange to a carboxyethenolamine anion $\left(\mathrm{C}_{17} \mathrm{H}_{33} \mathrm{COOCH}=\mathrm{CHNH}^{-}\right)\left(\underline{a}_{2}^{\prime}\right)$ and results in an oleic carboxylate ion at $m / z 281\left(\mathrm{C}_{17} \mathrm{H}_{33} \mathrm{CO}_{2}^{-}\right)\left(\underline{a}_{4}\right)$ by elimination of an azirine (41 Da) (Scheme $2 \mathbf{a}$, route $a$ ). This fragmentation pathway is supported by the source CAD product-ion spectrum of the $m / z 322$ ion (Figure $6 a)$, generated from the $m / z 562$ ion via source CAD. The spectrum is nearly identical to that arising from the $m / z 322$ precursors (Figure 6b), generated by source CAD of the authentic $N$-oleoylaminoethanol. The $[\mathrm{M}-\mathrm{H}]^{-}$ion of the $N$-oleoylaminoethanol at $\mathrm{m} / \mathrm{z}$ 324 is a labile ion, which dissociates to a prominent $N$-oleoylaminoethylen-1-ol ion at $m / z 322\left(\underline{a}_{2}\right)$ via a $\mathrm{H}_{2}$ loss, when subjected to a collision energy of $20 \mathrm{eV}$ (data not shown), which is $15 \mathrm{eV}$ lower than that optimized for ceramides. The loss of $\mathrm{H}_{2}$ mainly involves the two non-exchangeable hydrogens bonded to the ethanol backbone, as evidenced by the product-ion spectrum of the H-D exchanged analogs of the $m / z 325$ ion (Figure 6c), which contains a prominent ion of $m / z 323$, corresponding to a $\mathrm{H}_{2}$ loss. At a collision energy of $32 \mathrm{eV}$, the product-ion spectrum of the $m / z 324$ ion (Figure 6d) is nearly identical to that obtained from $\mathrm{m} / \mathrm{z} 322$ (Figures 6a and $b$ ), demonstrating that formation of the $m / z 322$ ion from $m / z 324$ via a $\mathrm{H}_{2}$ loss is indeed, the primary step that leads to further fragmentations.

The $m / z 306\left(\underline{a}_{3}\right)$ is the most prominent ion observed for d18:1/18:1-Cer (Figure 3a). The configuration of the ion was previously proposed [6-8], and the ion was thought to arise from $[\mathrm{M}-\mathrm{H}]^{-}$by a simultaneous losses of the LCB as an aldehyde and $\mathrm{a}_{2} \mathrm{O}$ involving two exchangeable hydrogens $[7,8]$. However, a domi- 


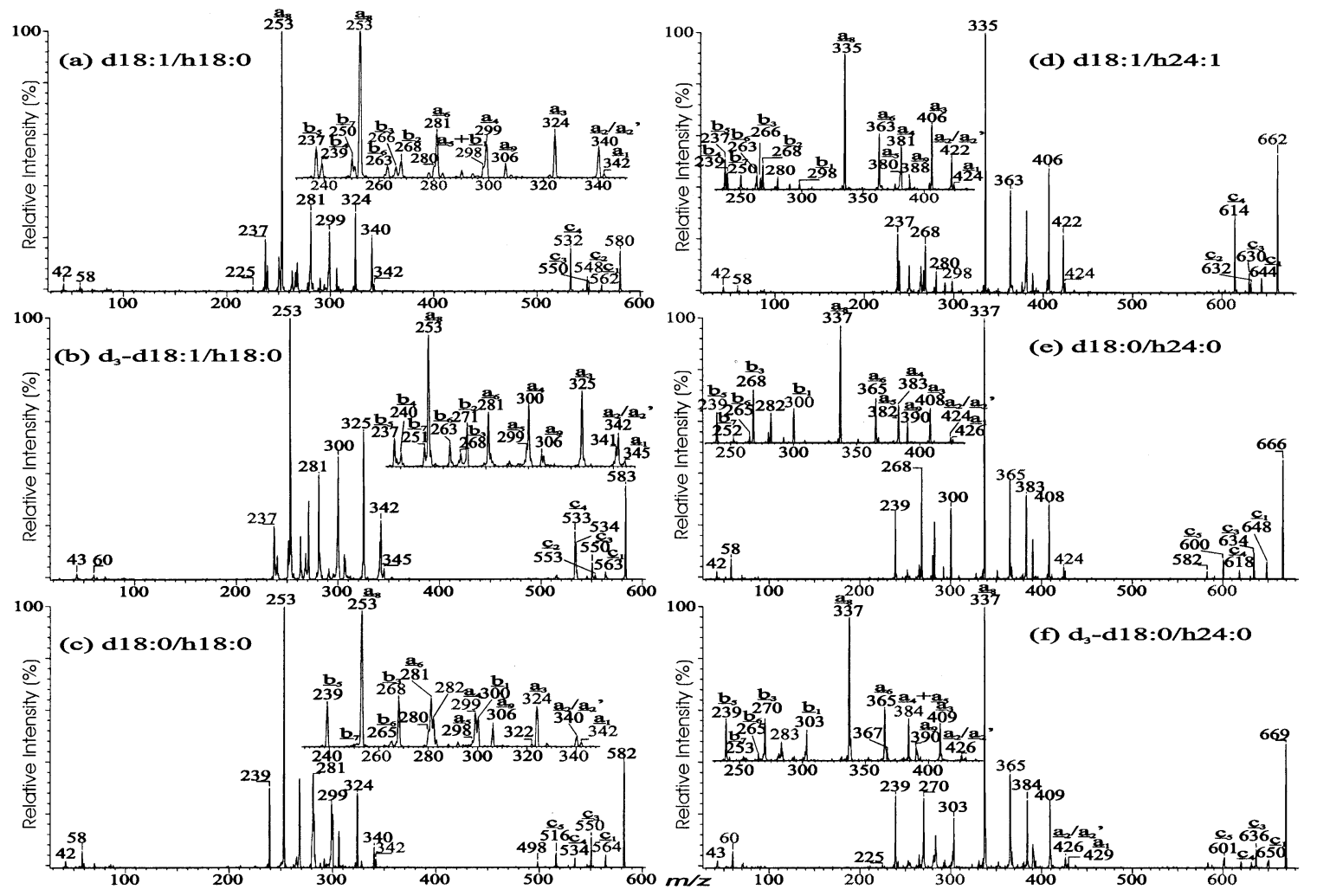

Figure 7. The product-ion spectra of the $[\mathrm{M}-\mathrm{H}]^{-}$ions of (a) d18:1/h18:0-Cer at $\mathrm{m} / \mathrm{z} 580$, (b) $\mathrm{d}_{3}$-d18:1/h18:0-Cer at $\mathrm{m} / \mathrm{z}$ 583, (c) d18:0/18:0-Cer at $\mathrm{m} / \mathrm{z}$ 582, (d) d18:1/h24:1-Cer at $\mathrm{m} / \mathrm{z}$ 662, (e) d18:0/h24:0-Cer at $m / z$ 666, and (f) $\mathrm{d}_{3}$-d18:0/h24:0-Cer at $m / z 669$.

nant analogous ion of $m / z 307$ was observed for $\mathrm{d}_{2}-18$ : 1/18:1-Cer (Figure 3b), indicating that mainly one exchangeable hydrogen participating in the loss. As shown in Figure 6d, the $m / z 324$ ion also gives $m / z 306$ $\left(a_{3}\right)$, probably by loss of $\mathrm{H}_{2} \mathrm{O}$ (Scheme $2 \mathrm{a}$, route $b$ ). The $\mathrm{m} / \mathrm{z} 306$ ion is also present in the source-CAD production spectrum of the $m / z 544$ ion $\left(562-\mathrm{H}_{2} \mathrm{O}\right)$ (Figure 3d). Therefore, the $m / z 306$ ion may arise from the consecutive dissociation steps, which involve an initial loss of $\mathrm{H}_{2} \mathrm{O}$ from $[\mathrm{M}-\mathrm{H}]^{-}$, followed by loss of the LCB as an aldehyde (loss of $238 \mathrm{Da}$ ) or via a reverse process, in which a $\mathrm{N}$-acylaminoethanol arising from loss of the LCB as an aldehyde was primarily formed, followed by a $\mathrm{H}_{2} \mathrm{O}$ loss.

As shown in Figure 6e, the $\mathrm{m} / \mathrm{z} 306$ ion $\left(\underline{a}_{3}\right)$ yields ions at $m / z 279$ and $263\left(\underline{a}_{6}\right)$, when further subjected to CAD. The latter ion likely arises from loss of $\mathrm{CH}_{2}=\mathrm{CHNH}_{2}$ and consistent with the observation of the $\mathrm{m} / \mathrm{z} 42$, corresponding to a $\mathrm{CH}_{2}=\mathrm{CHNH}^{-}$ion (Scheme $2 \mathrm{a}$, route $\left.b^{\prime}\right)$. The losses are further confirmed by observation of the $m / z 363$ and $347\left(a_{6}\right)$ ions in the product-ion spectrum of the analogous precursor ion of $\mathrm{m} / \mathrm{z} 390$ (Figure 6f), arising from d18:1/24:1-Cer. The observation of the fragment ions arising from further dissociation of $\mathrm{m} / \mathrm{z}$ 306 appears to be consistent with the structure of the $m / z 306$ ion $\left(a_{3}\right)$, previously proposed [6-8]. Another ion reflecting the fatty acid substituent of the molecule was observed at $\mathrm{m} / \mathrm{z} 280\left(\underline{a}_{5}\right)$, which can also arise from further dissociation of the $\mathrm{N}$-oleoylaminoethanol intermediate $(\mathrm{m} / \mathrm{z} 324)$ (Figure $6 \mathrm{~d}$ ) by expulsion of an oxirane (Scheme $\mathbf{2 a}$, route $c$ ).

The apparent distinction of the product-ion spectra of the $\mathrm{N}$-acylsphinganine from that of the $\mathrm{N}$-acylsphingosine is that the $\left[\mathrm{M}-\mathrm{H}-\mathrm{HCHO}^{-}\right.$ion is absent in the spectra of the former, when acquired under an optimal collision energy. This permits structural differentiation of ceramides between these two subclasses [6-8]. As shown in Figure 4a, the product-ion spectrum of the $[\mathrm{M}-\mathrm{H}]^{-}$ion of d18:0/18:0-Cer at $\mathrm{m} / \mathrm{z} 566$, contains the $\mathrm{m} / \mathrm{z} 534$ ion $\left(\underline{c}_{3}\right)$, corresponding to loss of $\left(\mathrm{H}_{2}+\mathrm{HCHO}\right)$, and the $m / z 536$ ion corresponding to HCHO loss is not observed. The $\mathrm{m} / \mathrm{z} 536$ ion becomes observable when obtained at low collision energy (data not shown). This result indicates that the $\mathrm{m} / \mathrm{z} 536$ ion may be formed. However, the ion is not stable and undergoes different $\mathrm{H}_{2}$ losses, of which one involves the participation of an exchangeable hydrogen, to form a more stable ion of $m / z 534\left(\left[566-\left(\mathrm{H}_{2}+\mathrm{HCHO}\right)\right]^{-}\right.$. This is shown by the product-ion spectrum of $\mathrm{d}_{2}-\mathrm{d} 18$ : 0/18:0-Cer (Figure $4 \mathrm{~b}$ ), which contains ions at $\mathrm{m} / \mathrm{z} 536$ and 535, corresponding to loss of $\left(\mathrm{H}_{2}+\mathrm{HCHO}\right)$ and $(\mathrm{HD}+\mathrm{HCHO})$, respectively. The $\mathrm{m} / \mathrm{z} 534$ ion $\left(\underline{c}_{3}\right)$ may be similar to the $[\mathrm{M}-\mathrm{H}-\mathrm{HCHO}]^{-}$ion observed for d18:1/nFA-Cer (Figure 3). This assumption is based on the findings that the source CAD product-ion spectrum of the $\mathrm{m} / \mathrm{z} 534$ ion (Figure $5 \mathrm{c}$ ) arising from d18:0/18:0- 
(a)

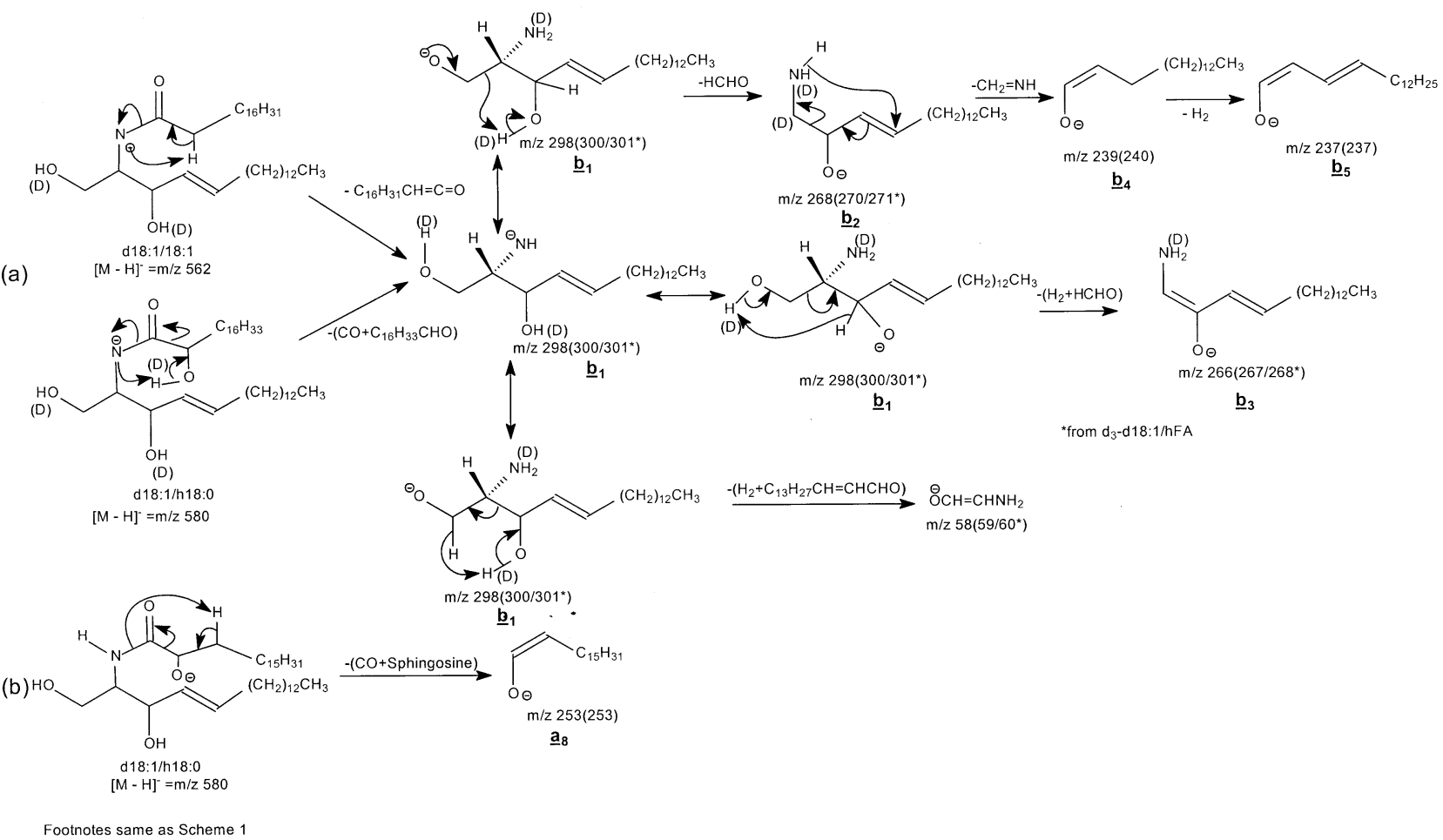

Scheme 3

Cer is similar to that of the $\mathrm{m} / \mathrm{z} 532$ ion $\left(\underline{c}_{2}\right)$ ([562 $\mathrm{HCHO}]$ ) (Figure 5a), but is readily distinguishable from that of $m / z 530\left(c_{3}\right)\left(\left[562-\left(\mathrm{H}_{2}+\mathrm{HCHO}\right)\right]\right)$ (Figure $\left.5 b\right)$, arising from $\mathrm{d} 18: 1 / 18: 1-C e r$. The product-ion spectrum of the $m / z 536$ ion (Figure 5f) from $d_{2}$-d18:0/18:0-Cer is also similar to that of the $\mathrm{m} / \mathrm{z} 534$ (Figure $5 \mathrm{~d}$ ), but different from that of the $m / z 531$ (Figure 5e), arising from $d_{2}-18: 1 / 18: 1-C e r$.

The above fragmentation pathways and the assignment of the fragment ions were further illustrated by the product-ion spectra of d18:1/24:1-Cer (Figure 3c) and d18:0/24:0-Cer (Figure 4c) and the H-D exchanged analog of $\mathrm{d}_{2}-\mathrm{d} 18: 0 / 24: 0-C e r$ (Figure $4 \mathrm{~d}$ ). The fragment ions referring to structural information of the fatty acid substituent and the LCB of the ceramides included in this study are listed in Table 1.

$N-\alpha$-Hydroxysphingosine and $N-\alpha-H y d r o x y s p h i n g a n i n e$. It has been previously reported in the tandem mass spectrometric study of the $[\mathrm{M}+\mathrm{Li}]^{+}$ions of ceramides $[1,7,8]$ that the cleavage of the $\mathrm{C}-\mathrm{C}$ bond between the carbonyl and the $\alpha$-carbon of the fatty acyl moiety ( $\alpha$-cleavage) is facilitated by the presence of the $\alpha$-hydroxyl group of the fatty acyl substituent. This feature is also observed for the $[\mathrm{M}-\mathrm{H}]^{-}$ions, when subjected to CAD. As shown in Figure $7 \mathrm{a}$, the product-ion spectrum of the $[\mathrm{M}-\mathrm{H}]^{-}$ion of d18:1/h18:0-Cer at $\mathrm{m} / \mathrm{z} 580$ contains a prominent ion at $\mathrm{m} / \mathrm{z} 253\left(\underline{a}_{8}\right)$, representing a deprotonated heptadecanoylaldehyde anion $\left(\mathrm{C}_{15} \mathrm{H}_{31} \mathrm{CH}=\mathrm{CH}-\mathrm{O}^{-}\right)$formed by a simultaneous losses of $\mathrm{CO}$ and the sphingosine (Scheme $3 \mathbf{b}$ ). The cleavage of the bond also results in $m / z 298\left(\underline{b}_{1}\right)$, likely a deprotonated sphingosine ion, which is also present in the spectra of d18:1/nFA-Cer (Figures 3a and c). An analogous ion of sphinganine was observed at $\mathrm{m} / \mathrm{z}$ 300 in all the product-ion spectra of d18:0/nFA-Cer (Figure 4) and d18:0/hFA (Figures 7c and e). The $\mathrm{m} / \mathrm{z}$ 298 ion is very labile and dissociates to ions at $\mathrm{m} / z 268$ $\left(\underline{b}_{2}\right)$ and $266\left(\underline{b}_{3}\right)$ by loss of $\mathrm{HCHO}$ and $\left(\mathrm{H}_{2}+\mathrm{HCHO}\right)$, respectively. This is shown by the product-ion spectrum of the $\mathrm{m} / \mathrm{z} 298$ ion (Figure $8 \mathrm{a}$ ), generated by source CAD of a d18:1/hFA-Cer mixture. The fragment ions are similar to that observed from the sphingosine standard (Figure $8 \mathrm{~b}$ ). The fragmentation pathways (Scheme 3a) are consistent with the earlier notion that the $\left[(\mathrm{M}-\mathrm{H})-\mathrm{HCHO}^{-}\right.$and $[(\mathrm{M}-\mathrm{H})$ $\left.-\left(\mathrm{HCHO}+\mathrm{H}_{2}\right)\right]^{-}$ions arising from the $[\mathrm{M}-\mathrm{H}]^{-}$ ions of $\mathrm{d} 18: 1 / \mathrm{nFA}$-Cer result from the similar cleavages (Scheme 1). The product-ion spectrum of the [M $-\mathrm{H}]^{-}$ion of the synthetic sphinganine at $\mathrm{m} / \mathrm{z} 300$ (data not shown, the sphinganine yields very few $\mathrm{m} / \mathrm{z}$ 300 ions) contains the $\mathrm{m} / \mathrm{z} 268$ ion arising from loss of $\left(\mathrm{HCHO}+\mathrm{H}_{2}\right.$ ), and the $\mathrm{m} / \mathrm{z} 270$ ion from loss of $\mathrm{HCHO}$ is not present. These results are similar to that observed for d18:0/nFA-Cer, in which only the $\left(\mathrm{HCHO}+\mathrm{H}_{2}\right)$ loss can occur and consistent with the fragmentation pathway leading to the formation of the $\left[(\mathrm{M}-\mathrm{H})-\left(\mathrm{HCHO}+\mathrm{H}_{2}\right)\right]^{-}$ion as described for d18:0/nFA-Cer (Scheme 1b).

Another feature ion for d18:1/h18:0-Cer (Figure 7a) and d18:0/h18:0-Cer (Figure 7c) was observed at $\mathrm{m} / \mathrm{z}$ $306\left(a_{9}\right)$, likely arises from $\mathrm{m} / \mathrm{z} 324$ via a $\mathrm{H}_{2} \mathrm{O}$ loss. The analogous ions were observed at $\mathrm{m} / \mathrm{z} 388$ and 390 for d18:1/h24:1-Cer (Figure 7d) and d18:0/h24:0-Cer (Figure $7 \mathrm{e})$, respectively. The identity of the 18:1-LCB 


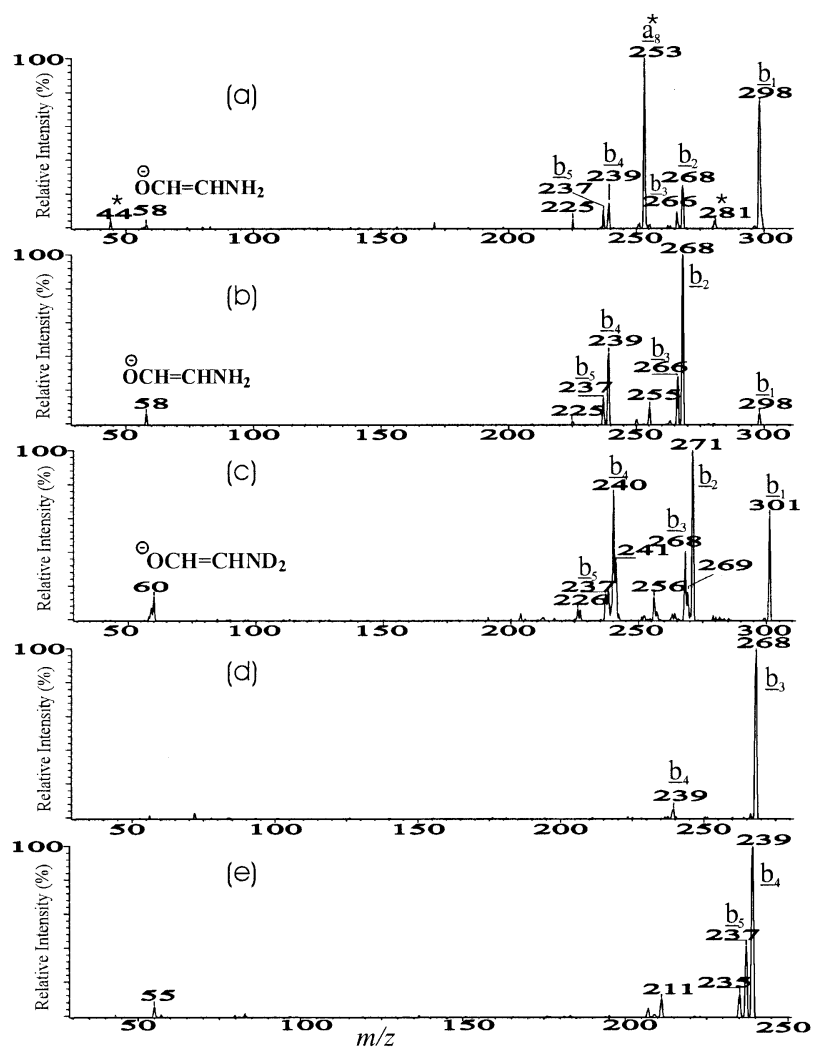

Figure 8. The source-CAD product-ion spectra of (a) $\mathrm{m} / \mathrm{z} 298$, generated by source CAD of d18:1/h18:0-Cer $(m / z 580)$, (b) the [M $-\mathrm{H}]^{-}$ion of sphingosine at $m / z 298$, (c) the deprotonated anion of $\mathrm{d}_{3}$-sphingosine at $\mathrm{m} / \mathrm{z} 301$, prepared by H-D exchange, (d) the $\mathrm{m} / \mathrm{z}$ 268 ion, and (e) the $\mathrm{m} / \mathrm{z} 239$ ion. The $\mathrm{m} / \mathrm{z} 268$ and 239 were generated by source CAD of the $[\mathrm{M}-\mathrm{H}]^{-}$ions of sphingosine. The $m / z 298$ (panel a) corresponds to the $[\mathrm{M}-\mathrm{H}]^{-}$ions of both a sphingosine and a $N$ - $\alpha$-hydroxystearoylamide. The ions marked with an asterisk arise from fragmentation of the $N$ - $\alpha$-hydroxystearoylamide.

moiety of the molecules is recognized by the presence of $m / z 237$, along with the $m / z 239$ ion. The latter ion is a major fragment ion observed in the product-ion spectrum of $m / z 298$ (Figure $8 \mathrm{~b}$ ). Therefore, the $\mathrm{m} / \mathrm{z} 239$ ion $\left(\underline{b}_{4}\right.$, Scheme 3a) observed for d18:1/h18:0-Cer probably originates from further decomposition of $m / z 298\left(\underline{b}_{1}\right)$, which yields ions at $m / z 268\left(\underline{b}_{2}\right)$ and $266\left(\underline{b}_{3}\right)$, as described earlier. The $\mathrm{m} / \mathrm{z} 268$ ion undergoes further decomposition to $m / z 239\left(\underline{b}_{4}\right)$ by loss of $\mathrm{NH}=\mathrm{CH}_{2}(29$ $\mathrm{Da})$, followed by another $\mathrm{H}_{2}$ loss to $m / z 237\left(\underline{b}_{5}\right)$. This fragmentation pathway is supported by the source CAD product-ion spectra of the $\mathrm{m} / \mathrm{z} 268$ (Figure $8 \mathrm{~d}$ ) and $\mathrm{m} / \mathrm{z} 239$ ions (Figure 8e) and consistent with the presence of an analogous ion of $m / z 240$ (mass shift of $1 \mathrm{u}$ ) in the product-ion spectra of $\mathrm{d}_{3}$-d18:1/18:0-Cer (Figure $7 \mathrm{~b}$ ), and $\mathrm{d}_{3}$-d18:1-LCB (Figure 8c). The $m / z 239$ ion is not present in the product-ion spectra of $\mathrm{d} 18: 1 / \mathrm{nFA}-\mathrm{Cer}$ (Figures 3a and c), probably attributable to the fact that the abundance of the sphingosine anion of $\mathrm{m} / \mathrm{z} 298$ produced by a ketene loss process is too low to initiate a secondary dissociation to $\mathrm{m} / \mathrm{z} 239$. This is also consistent with the low abundance of the $\mathrm{m} / \mathrm{z} 268$ ion in the

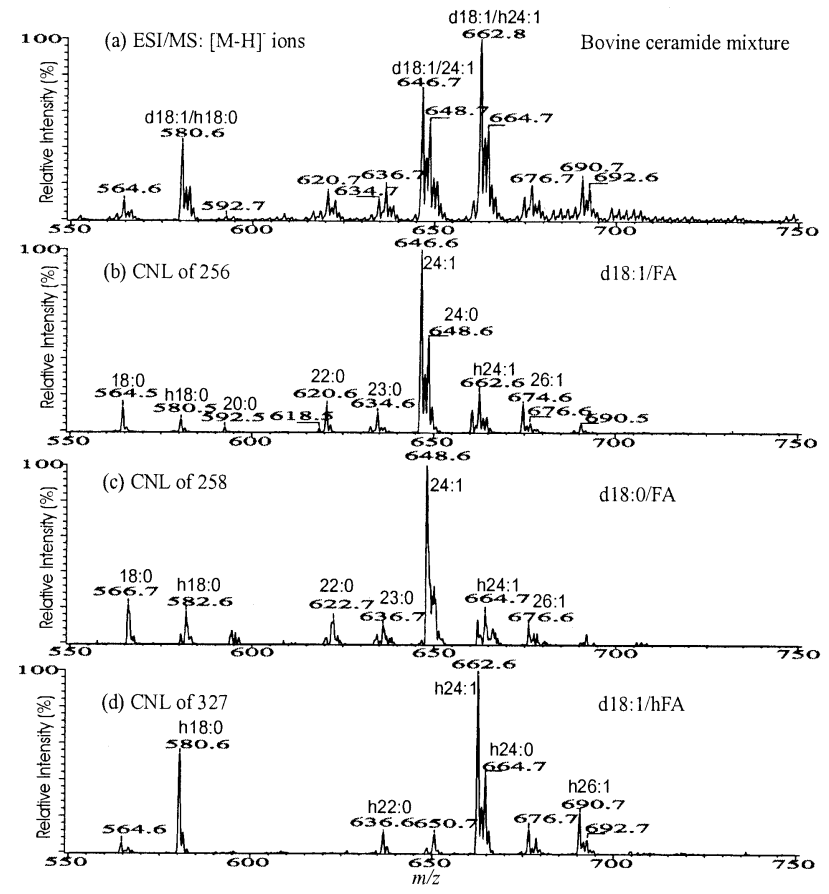

Figure 9. The ESI/MS of (a) the $[\mathrm{M}-\mathrm{H}]^{-}$ions of bovine brain ceramides. The TIC profiles of the $[\mathrm{M}-\mathrm{H}]^{-}$ions of the same mixture obtained by CNL scannings of 256 (b), 258 (c), and 327 (d), identify the subclasses of d18:1/FA-, d18:0/FA- and d18:1/hFACer in the mixture, respectively.

spectra. The fragment ions reflecting the identities of the fatty acid substituent and the LCB of the ceramides included in this study are listed in Table 1.

\section{Identification of Ceramide Subclasses via Linked Scannings}

Precursor ion scan of $m / z 264$ has been previously used for identification and quantification for ceramide in biological extract [2]. However, identification of ceramide subclasses in mixture by constant neutral loss scanning has not been described. As mentioned earlier, the fragment ion of $[\mathrm{M}-\mathrm{H}-256]^{-}\left(a_{1}\right)$, arising from the combined losses of $\mathrm{H}_{2} \mathrm{O}$ and the LCB as an aldehyde is a common ion observed for ceramides with a 18:1$\mathrm{LCB}$, whereas the $[\mathrm{M}-\mathrm{H}-258]^{-}$ion is observed for ceramide subclass with a 18:0-LCB. Therefore, identification of ceramide subclasses with a 18:1-LCB or with a 18:0-LCB in mixtures can be achieved by CNL scanning of 256 and 258, respectively. This is shown in Figures $9 \mathrm{~b}$ and $c$, which illustrate the precursor-ion spectra obtained by CNL of 256 and 258, respectively. The former spectrum contains ions at $\mathrm{m} / \mathrm{z} 564,592,620,634,646$, 648 , and 674 , representing the $\mathrm{N}$-acylsphingenine with a 18:0, 20:0, 22:0, 23:0, 24:1, 24:0, and 26:1 fatty acyl moiety, respectively, and ions at $\mathrm{m} / \mathrm{z} 580$ and 662, arising from d18:1/h18:0-Cer and d18:1/h24:1-Cer, respectively. The TIC profile of Figure $9 \mathrm{~b}$ is close to that of the ESI mass spectrum (Figure 9a), representing the $[\mathrm{M}-\mathrm{H}]^{-}$species, however, the abundance of the ions 


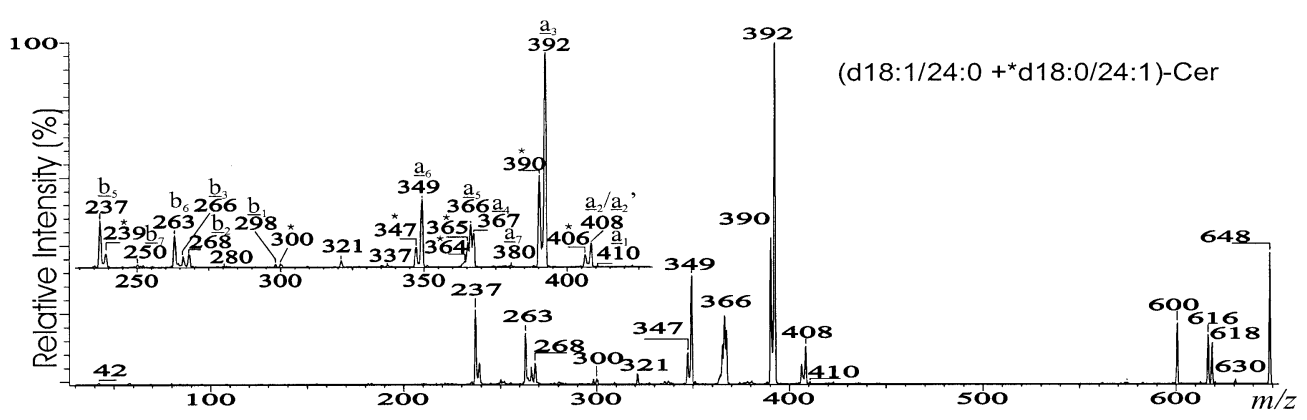

Figure 10. The product-ion spectrum of the $m / z 648$ ion from the bovine brain ceramide. The tandem mass spectrum contains two sets of ions reflecting the major species of the d18:1/24:0-Cer and a minor species of *d18:0/24:1-Cer. The ions from minor component are labeled with an asterisk.

of $m / z 580$ and 662 has been suppressed. This is attributable to the fact that the $[\mathrm{M}-\mathrm{H}-256]^{-}\left(a_{3}\right)$ ion observed for the $\mathrm{N}$-acylsphingenine is the most prominent, whereas the same ion observed for $N-\alpha$-hydroxyacylsphingenine is less abundant. The major $N$-acylsphinganines in the mixture were observed at $\mathrm{m} / \mathrm{z} 566,582$, $622,636,648,664$, and 676 reflecting the 18:0, h18:0, 22:0, 23:0, 24:1, h24:1, and 26:1 fatty acyl moiety, respectively. However, the ions can also arise from the second isotopic species from d18:1/FA-Cer.

The $m / z 648$ is the major ion observed in both the tandem mass spectra obtained by CNL of 256 (panel b) and of 258 (panel c), indicating that the ion may represent a ceramide consisting of a 18:1- and 18:0-LCB. Indeed, the product-ion spectrum of the $\mathrm{m} / \mathrm{z} 648$ ion (Figure 10), contains a major set of ions at $m / z 237\left(\underline{b}_{5}\right)$ and $392\left(\underline{a}_{3}\right)$, arising from the d18:1/24:0-Cer and a minor set of ions at $\mathrm{m} / z 239\left(\underline{b}_{5}\right)$ and $390\left(\underline{a}_{3}\right)$, reflecting the d18:0/24:1-Cer isomer. The structure assignment of the major 18:1/24:0-Cer species is further confirmed by the ion sets of $m / z 349\left(a_{6}\right), 367\left(a_{4}\right)\left(\mathrm{RCOO}^{-}\right), 366\left(a_{5}\right)$, and $408\left(\underline{a}_{2}\right)$, reflecting the 24:0-FA and of $m / z 298\left(\underline{b}_{1}\right)$, $268\left(\underline{b}_{2}\right), 266\left(\underline{b}_{3}\right)$, and $250\left(\underline{b}_{7}\right)$, reflecting the 18:1-LCB. Whereas the minor d18:0/24:1-Cer species is confirmed by the presence of the ions of $m / z 347\left(\underline{a}_{6}\right), 365\left(\underline{a}_{4}\right), 364$ $\left(\underline{a}_{5}\right), 406\left(\underline{a}_{2}\right)$, arising from the 24:1-FA and of the $m / z 300$ ion $\left(\underline{b}_{1}\right)$ that confirms the 18:0-LCB.

\section{Conclusions}

A complete structural identification of ceramide can be easily achieved by tandem quadrupole mass spectrometry with ESI in the negative-ion mode. However, the structurally informative ions can only be generated by CAD of the $[\mathrm{M}-\mathrm{H}]^{-}$ions, which are significantly less detectable than the $[\mathrm{M}+\mathrm{Cl}]^{-}$adduct ion species and the $\left[\mathrm{M}+\mathrm{Li}^{+}\right.$ions in positive-ion mode by ESI. Discrimination in detection among different ceramide subclasses also occurs. Although the TIC profiles of the ceramide obtained by ESI/MS and ESI/MS/MS described in this study may reflect the relative intensity of the individual species of the same subclass in mixtures, they can not reflect the relative amount among the species in different subclasses. Under both high-energy and low-energy $\mathrm{CAD}$, the major fragment ions observed for $[\mathrm{M}-\mathrm{H}]^{-}$ions in negative-ion mode and for the $[\mathrm{M}+\mathrm{Li}]^{+}$ions in positive-ion mode appear to arise from the similar bond cleavages $[1,8]$. However, the structurally informative product ions arising from the $[\mathrm{M}+\mathrm{Li}]^{+}$adduct ion [1] are less abundant than those arising from the $[\mathrm{M}-\mathrm{H}]^{-}$ion, when subjected to low-energy CAD at the optimal collision energy. This is advantageous for structural characterization of ceramide using the product-ion spectrum of the $[\mathrm{M}-\mathrm{H}]^{-}$ion. The application of this method in the identification of ceramide species in cell extracts is currently in progress.

\section{Acknowledgments}

The authors are grateful to Alan Bohrer for the technical support. They express special thanks to Jeff Kao of the NMR facility, Department of Chemistry Washington University, for NMR analysis. This research was supported by U.S. Public Health Service grants (P41RR-00954, R37-DK-34388, P60-DK-20579, and P01-HL-57-278 and a grant (996003) from the Juvenile Diabetes Foundation.

\section{References}

1. Hsu F. F.; Turk J.; Stewart M. E.; Downing D. T. Structural Studies on Ceramides as Lithiated Adducts by Low Energy Collisional-Activated Dissociation Tandem Mass Spectrometry with Electrospray Ionization. J. Am. Soc. Mass Spectrom., in press.

2. Gu, M.; Kerwin, J. L.; Watts, J. D.; Aebersold, R. Ceramide Profiling of Complex Lipid Mixtures by Electrospray Ionization Mass Spectrometry. Anal. Biochem. 1997, 244, 347-356.

3. Raith, K.; Neubert, R. H. H. Liquid Chromatography-Electrospray Mass Spectrometry and Tandem Mass Spectrometry of Ceramides. Anal. Chim. Acta 2000, 403, 295-303.

4. Raith, K.; Neubert, R. H. H. Structural Studies on Ceramides by Electrospray Tandem Mass Spectrometry. Rapid Commun. Mass Spectrom. 1998, 12, 935-938.

5. Vietzke, J. P.; Brandt, O.; Abeck, D.; Rapp, C.; Strassner, M.; Schreiner, V.; Hintze, U. Comparative Investigation of Human Stratum Corneum Ceramides. Lipids 2001, 36, 299-304.

6. Costello, C. E.; Vath, J. E. Methods in Enzymology; In: McCloskey, J. A., Ed.; Academic Press: San Diego, CA, 1990; p. 738-768 Vol. CXCIII.

7. Ann, Q.; Adams, J. Structural Determination of Ceramides and Neutral Glycosphingolipids by Collisional Activation of [M + Li] ${ }^{+}$ions. J. Am. Soc. Mass Spectrom. 1992, 3, 260-263. 
8. Ann, Q.; Adams, J. Structural-Specific Collision-Induced Fragmentations of Ceramides Cationized with Alkali-Metal Ions. Anal. Chem. 1993, 65, 7-13.

9. Hsu, F. F.; Bohrer, A.; Turk, J. Electrospray Ionization Tandem Mass Spectrometric Analysis of Sulfatide. Determination of Fragmentation Patterns and Characterization of Molecular Species Expressed in Brain and in Pancreatic Islets . Biochim. Biophys. Acta 1998, 1392(2-3), 202-216.

10. Hsu, F. F.; Turk, J. Studies on Phosphatidylglycerol with Triple Quadrupole Tandem Mass Spectrometry with Electrospray Ionization: Fragmentation Processes and Structural Characterization. J. Am. Soc. Mass Spectrom. 2001, 12, 1036-1043.
11. Zhu, J.; Cole, R. B. Formation and Decompositions of Chloride Adduct Ions, $\left[\mathrm{M}+\mathrm{Cl}^{-}\right.$, in Negative Ion Electrospray Ionization Mass Spectrometry. J. Am. Soc. Mass Spectrom. 2000, 11, 932-941.

12. Zhu, J.; Cole, R. B. Ranking of Gas-Phase Acidities and Chloride Affinities of Monosaccharides and Linkage Specificity in Collision-Induced Decompositions of Negative Ion Electrospray-Generated Chloride Adducts of Oligosaccharides. J. Am. Soc. Mass Spectrom. 2001, 12, 1193-1204.

13. Harrison, A. G. Chemical Ionization Mass Spectrometry. CRC Press: Florida, 1983 [chapter II]. 